\title{
Developing a collaborative HBIM to integrate Tangible and Intangible Cultural Heritage
}

\section{Abstract \\ Purpose:}

The purpose of this paper is to report on the development of a collaborative Heritage BIM (HBIM) of a $19^{\text {th }}$ Century multi-building industrial site in the UK. The buildings were Grade II listed by Historic England for architectural and structural features. The buildings were also a key element of the industrial heritage and folklore of the surrounding area. As the site was due to undergo major renovation work, this project was initiated to develop a HBIM of the site that encapsulated both tangible and intangible heritage data.

\section{Design/methodology/approach:}

The design of the research in this study combined multiple research methods. Building on an analysis of secondary data surrounding HBIM, a Community of Practice (CoP) was established to shape the development of a Heritage BIM Execution Plan (HBEP) and underpin the collaborative BIM development. The tangible HBIM geometry was predominantly developed using a scan to BIM methodology, whereas intangible heritage data was undertaken using unstructured interviews and a focus group used to inform the presentation approach of the HBIM data.

\section{Findings:}

The project produced a collaboratively generated multi-building Heritage BIM. The study identified the need for a dedicated HBEP which varies from prevailing BEPs on construction projects. Tangible geometry of the buildings were modelled to LOD3 of the Historic England guidelines. Notably, the work identified the fluid nature of intangible data and the need to include this in a HBIM to fully support design, construction and operation of the building after renovation. A methodology was implemented to categorise intangible heritage data within a BIM context and an approach to interrogate this data from within existing BIM software tools. 
Originality/Value:

The work has presented an approach to the development of HBIM for large sites containing multiple buildings/assets. The framework implemented for a HBEP can be reproduced by future researchers and practitioners wishing to undertake similar projects. The method for identifying and categorising intangible heritage information through the developed Level of Intangible Cultural Heritage (LOICH), was presented as new knowledge. The development of HBIM to bring together tangible and intangible data has the potential to provide a model for future work in the field and augment existing BIM data sets used during the asset lifecycle.

Keywords: BIM, Heritage, Tangible, Intangible, Cultural, BIM Execution Plan, Architecture 


\section{Introduction}

The use of the Building Information Modelling (BIM) process and associated technologies is significantly impacting on all aspects of the built environment. The term BIM has itself given rise to a range of variations in terms of specific definition. Whilst it is generally agreed that BIM brings together Process, Technology and Policy (Succar, 2009), Dawood and Vukovic (2015) further extend this to add another 'pillar' to include people as a critical element in the process. Through the prevailing BIM processes, such as those defined through the UK Level 2 standards (BSI, 2015), the creation of an information rich 3D geometric model starts early in the development cycle (Mordue et al., 2015). This model is then continually augmented with a range of non-graphical data which can support all aspects of design and construction, eventually leading to the creation of data to support an assets operation and maintenance (Pärn and Edwards, 2017). The use of BIM on projects involving refurbishment and adaption of existing buildings faces a range of additional challenges (Volk et al., 2014). One of the challenges includes the creation of an initial model with Edwards (2017) noting that the current development of Existing BIM (EBIM) or can be a costly and time-consuming process.

The use of BIM in the renovation of existing heritage buildings has been noted as an approach to capture and digitise historic data which can then be used at all stages of the lifecycle (Volk et al., 2014). This has led to the increase in the amount of research undertaken in this specific paradigm of Heritage BIM (HBIM). Dore and Murphy (2012) postulate that one of the main reasons for the increase is also aligned to the more readily available access to laser scanning and photogrammetry. Garagnani (2015) and Marzouk et al. (2016) emphasise the ongoing need for HBIM highlighting the benefit of capturing history and culture in a single repository, where all model elements, data and entities are integrated. Pauwels et al. (2013) noted that in order to fully depict a heritage asset, disparate information should be integrated with existing BIM tools that will document and combine all heritage information with accurate visualisations providing a holistic dataset that can be easily understood. Tommasi et al. (2016) discuss the benefit of integrating a range of data sets into a HBIM that supports management and conservation during future adaption work. These rich data sets provide the ability to undertake a more 
enhanced analysis of the cultural heritage of construction projects (Baik et al., 2015) and as such the 3D models created can be used for more than just visualization (Dore et al., 2015).

An increasing body of work relating to HBIM has focused on the creation of individual 3D geometric models depicting the tangible (or physical) aspect of cultural heritage (Fai and Sydor, 2013). Furthermore, published HBIM examples focus on an individual building or assets and there is a paucity of work discussing the use of collaborative practices used in their production. In order to ensure that all aspects of heritage are contained within the BIM dataset, both tangible and intangible heritage data is required as this can support future design, construction and operation. Intangible heritage information moves away from the physical to include elements such as skills, oral traditions and rituals which may relate to overall form and function of a building and can identify the reasoning behind the design (UNESCO, 2003). It has been noted that many HBIM models do not add information that is nonarchitectural (Saygi, 2013). Furthermore, Maxwell (2014) noted that a meaningful approach to the use of HBIM was 'non-existent', highlighting that such tangible details as material degradation were needed in addition to including intangible aspects such as in-use circumstances.

Based on the contextual backdrop provided, the aim of this study was the implementation of a collaborative BIM process leading to the generation of a HBIM that integrates both tangible and intangible cultural heritage information within a BIM technological environment. A multi methods research approach was implemented to develop a HBIM. This involved collaboration with a number of stakeholders related to the identified project, which was a $19^{\text {th }}$ Century industrial site containing several listed buildings forming part of a heritage renovation project. The research objectives of the project were:

- Critically evaluate current BIM practices for the development of a Heritage BIM Execution Plan (HBEP) to support collaborative development

- Undertake data capture for both tangible and intangible heritage data using a qualitative data capture approach 
- Develop a method for defining a level of intangible cultural heritage for inclusion in development of a HBIM

- Implement the HBIM process and develop a digital model that incorporates both tangible and intangible heritage data

Through the implementation of the work the authors are seeking to provide a blueprint for future work in the field to develop HBIM with structured and defined tangible and intangible cultural heritage data.

To provide the underlying scope for this study, the following definitions are outlined:

- Tangible Cultural Heritage - the physical representation of the architectural and structural fabric of the buildings

- Intangible Cultural Heritage - cultural heritage information related to the buildings and site which are non-physical

\section{Prevailing Heritage BIM approaches}

BIM as a paradigm is focused on the philosophy of creating a database containing connected 3D geometric and informational data about the objects (Eastman et al., 2011). BIM, as a process, is now generally defined and is the use of digital models and data to support the full range of the lifecycle of a built asset, from design through to operation (NBS, 2016). Whilst BIM is often now referred to as a noun and a verb, the use of Heritage BIM (HBIM) is most often referred to as the development of an individual digital model (or repository) containing geometric information.

Volk et al. (2014) suggest that there are various methods for capturing survey data, which can subsequently be used in the development of a BIM. Along with existing documentation, laser scanning and photogrammetry is often seen as the starting point for HBIM, accurately capturing the buildings/sites physical and structural data (Khodier et al., 2016). In the UK, 3D laser scanning was 
identified by Historic England as an important aspect of the cultural heritage process and as such a guidance document '3D Laser Scanning for Heritage' was published in 2007 and then subsequently revised in 2018 (Historic England, 2018). The guidance covers issues surrounding available technologies, resolution and the procurement process. However, one of the key issues to understand is what should be modelled geometrically in 3 dimensions and the scope of any modelling to ensure cost effectiveness (Morrical, 2017). Tang et al. (2010) summarise the 'Scan to BIM' process in three distinct stages, including the capture of data in the form of a point cloud, pre-processing of data such as merging multiple scans together and finally the geometric modelling using a BIM authoring tool (Lopez et al., 2018). Whilst this can yield accurate results, it is noted by Xoing et al. (2013) that this is still a manual process and can be subject to mistakes and requires experienced operators.

Several authors have reported workflows for incorporating laser scan data into the BIM process and workflow which is now becoming a de-facto standard (Laing et al., 2015; Apollonio et al., 2017; Lopez et al., 2017). However, Counsell and Taylor (2017) highlight that a significant amount of time and cost is taken up when modelling the geometry of the HBIM from laser scan data. In order to counter this, they believe HBIM should focus on the production of lower resolution 'semantic' BIM which could provide a representation and then be linked to intangible data or even accurate scan data of the building where appropriate (DURAAK, 2016). Some previous work is seeking to resolve this critical issue by developing methods to automatically extract geometric objects from point cloud data (Wang et al., 2015). However, in a similar approach to the approach of Xiong et al. (2013), the work is based on the production of 2D polygons rather than full 3D geometric entities. Ochmann et al. (2016) did develop an approach to automatically generate indoor parametric models from point cloud data, whereas Sharif et al. (2017) developed an approach to automatically identify specific pieces of equipment within a dense point cloud. In order to remove this need to generate geometric models either manually or automatically, Poux et al. (2017) have began to develop semantic queries on point cloud data sets. Whilst this does not produce geometric entities it does provide the ability to integrate non graphical data directly into point clouds which could streamline usage in the BIM workflow. 
Where geometric modelling is undertaken using a manual process, there are some difficulties when using current software tools to develop the geometry of cultural heritage models (Bregianni, 2013). Some previous efforts in the field of HBIM have sought to adopt the power of BIM tools to generate repetitive architectural features in standardised libraries (Fai and Sydor, 2013) including such elements as columns (Apollonio et al., 2012). However, Logothetis et al., (2015) note that the non-standard aspect of heritage architecture provides challenges surrounding the implementation of HBIM as the built assets are comprised of components and materials whose geometry and characteristics are not representative of current building objects. Building deformities can also cause an issue in library creation, as they can differ widely and the properties of the original element may not match the current element properties. Folwell (2015) describes how this can be overcome by including "lateral and vertical deviation" information as non-graphical parameters of the $3 \mathrm{D}$ element.

Throughout the geometric modelling of the heritage asset, the Level of Detail (LOD) ensures that the model meets the requirement and the time/cost constraints in balance with the required outputs. To further support the issue of LOD for heritage-based projects, Historic England has defined four levels of graphical detail when generating 3D geometry in HBIM projects (Antonopoulou and Bryan, 2017). Whilst these provide a level of guidance during the development stage, there is yet to be a full global standard established for heritage projects and this has often led to individual projects developing their own bespoke standard (Folwell, 2015). Building on the work of the EU funded Valhalla Project in 2003, Counsell and Taylor (2017) proposed a framework for HBIM and cultural heritage that included integrating additional tangible heritage data through use of sensors and recording of materials. However, they also discuss the potential to include intangible aspects through inclusion of locationspecific intangible cultural heritage and using the HBIM for community engagement. 
The use of the BIM process for existing buildings is continually developing (Lin et al., 2016) and some previous research has investigated taking elements from the standardised UK 'Level 2' BIM process into the heritage domain. This has included the development of Employers Information Requirements (EIR) for heritage construction projects (Dwairi et al., 2017; Dwairi and Mahdjoubi, 2017). This approach focused on the geometric modelling of tangible assets but did not consider intangible heritage data. Jordan-Palomar et al. (2018) provided a critical review of current BIM protocols and heritage intervention approaches. Specifically, the work noted the lack of clarity of these approaches.

\subsection{Intangible Heritage Data in HBIM}

Vecco (2010) highlights the importance of intangible heritage, noting that whilst there is need to recognise and record material heritage, non-physical aspects are increasingly important. Lenzerini (2011) argues that cultural heritage is becoming increasingly important as the fusion of civilisations is leading to a level of uniformity across the globe, thus the need to record all aspects of cultural heritage related to historic buildings is becoming critical. UNESCO (2003) highlighted the need to record intangible data and have this geo-referenced including Web 2.0 recordings. Counsell and Taylor (2017) noted at the present time the inclusion of intangible data is based on a push of data from expert to participant and this can often require management to be maintained. However, with the emergence of social media and the now ubiquitous use of tagging using the 'hashtag' there exists a methodology to have more dynamic data aligned to the geometric objects (Donatao et al., 2018). One issue surrounding the use of 'uncontrolled' participatory input is the level of certainty of the information and the management of the quality of the data (ibid).

Dore \& Murphy (2012) did propose that a 3D digital geometric model could contain historical information about the creation, origin and chronology of heritage objects. These could then be linked to historical documents in different formats i.e. manuscripts, $2 \mathrm{~d}$ floor plans and sections, photos or voice recordings. Fai et al. (2011) also suggested that a BIM could contain non-graphical 'intangible' data 
Fassi et al (2016) postulated that more interactive functions within 3D models would be required to enhance the uptake and thus could support the inclusion of intangible heritage data within the context of HBIM. The authors suggested a 'read and write' mode where the model could be asked questions and VR could be used to compare present and past, and to assess and quantify the changes caused by time. Whilst there has been some limited previous research which has postulated the inclusion of intangible data within a HBIM, these have not been fully implemented. Furthermore, there appears no specific methodology to categorise the intangible data such that it aligns with prevailing approaches to BIM development. On many projects/buildings, the intangible data has shaped the form and function of the building and so this can impact any future renovation work.

\section{Research Approach and Methodology}

In order to achieve the aim of this wide-reaching study, the design of the research combined multiple research methods (Figure 1). Secondary data analysis, focused on prevailing issues surrounding HBIM, identified a number of issues relating to tangible and intangible heritage data. In addition a HBIM Community of Practice (CoP) was established (Pyrko et al., 2017) that engaged a number of researchers who were to be involved in the development of HBIM. Using a convenience-based sampling approach, the members of the CoP were selected from a cohort of postgraduate researchers who each had a range of practical experience of implementing the BIM processes and technologies in new build and renovation projects and could bring experiences to this study (Table 1). 


\begin{tabular}{|l|l|l|l|}
\hline CoP \#ID & Job Title & Industry Focus & $\begin{array}{l}\text { Years of BIM } \\
\text { Experience }\end{array}$ \\
\hline 1 & Digital Specialist & Architecture & 3 \\
\hline 2 & Digital Engineer & Civil Engineering & 2 \\
\hline 3 & BIM Technician & Architecture & 5 \\
\hline 4 & HBIM BIM Researcher & Architecture & 10 \\
\hline 5 & Architectural Technologist & Architecture & 3 \\
\hline 6 & Architectural Technologist & Architecture & 4 \\
\hline 7 & Quantity Surveyor & Construction Management & 6 \\
\hline 8 & Building Surveyor & Heritage Survey & 2 \\
\hline
\end{tabular}

Table 1: Community of Practice for HBIM development

The use of a CoP as a research approach to support this project was chosen as it provided the ability for the collaboration of like-minded individuals to focus on a specific research problem (Denscombe, 2008). Furthermore, the CoP approach was selected for this work as it mirrored the core concepts of the development of a collaborative HBIM. In particular Coombs et al. (2017) suggest that a CoP offers three main characteristics; shared domain of interest (the development of a HBIM), a community that interacts and learns (BIM development team) and development of shared practice (creation of new modelling approaches synthesised in a Heritage BEP). Initially, the use of the CoP in the research process helped to shape the development of a Heritage BIM Execution Plan (HBEP) which would underpin the implementation of the project. 


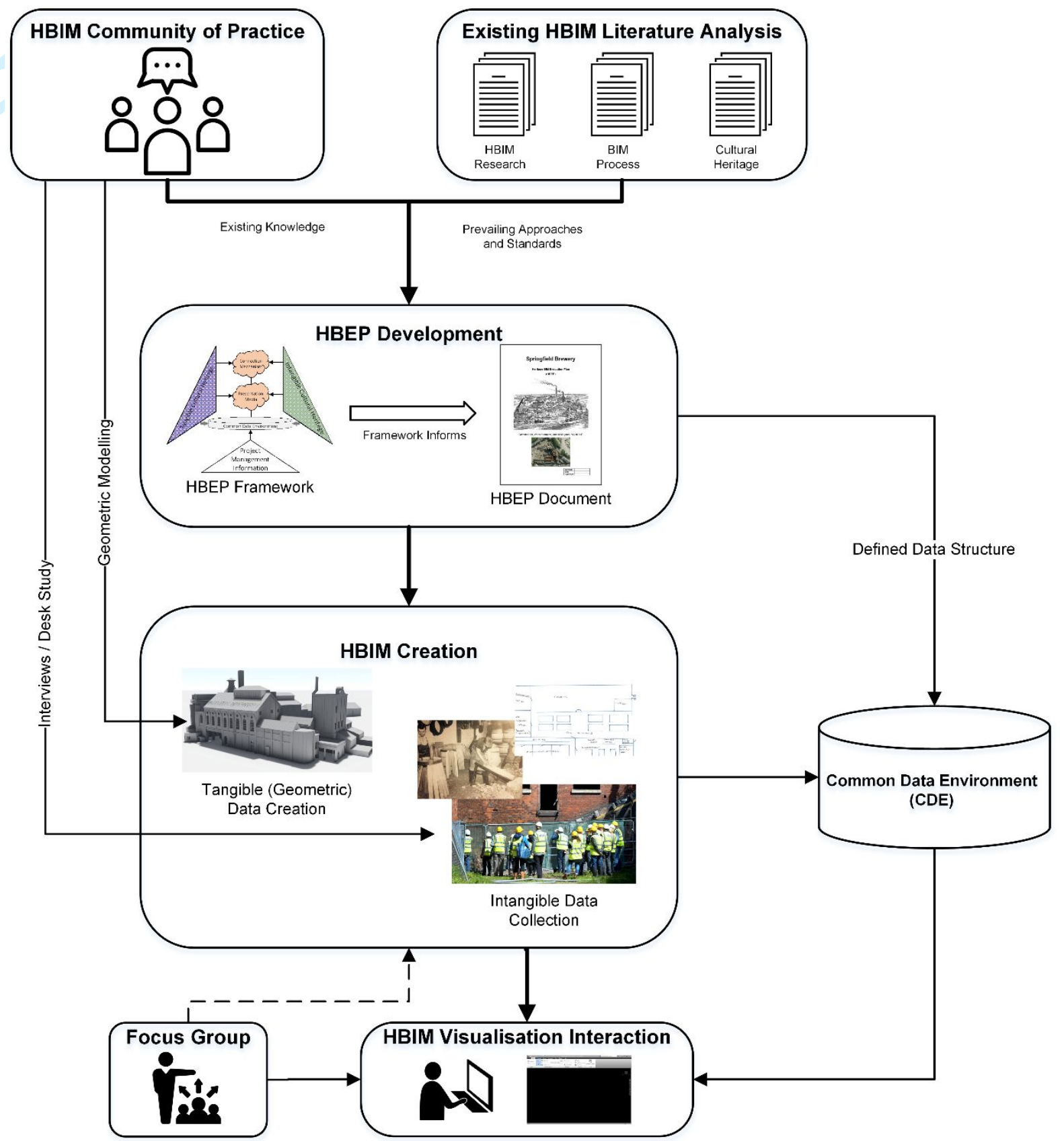

Figure 1: Research approach for the study

Following the development of the HBEP, the implementation of HBIM followed a three-phase approach to; a) develop tangible HBIM geometry, b) collate intangible heritage information and c) integrate these into a full HBIM database via a Common Data Environment. The collation of intangible heritage data was undertaken using unstructured interviews. A purposive sampling method was employed for the selection of interviewees and in particular a homogeneous approach was implemented 
whereby the individuals interviewed shared similar jobs and life experiences of working on the site during operation (Etikan et al., 2016) The interviews were undertaken during a site visit of previous employees of the site ( $\mathrm{n}=21$ ) who worked in the buildings in a range of various roles during the time period specified for the HBIM development. Further interviews $(n=7)$ were undertaken with other individuals who were engaged in the site operations and maintenance to develop further knowledge (Table 2). The interviews were facilitated by members of the CoP and an unstructured approach was taken as this allowed the participants to provide their own social realities and history of the buildings (Zang and Wildemuth, 2009). Furthermore, the use of a focused unstructured interview (Gray, 2013; Jamshed, 2014) allowed the interviewee to freely discuss topics pertaining to intangible data about the buildings, whilst also allowing the focus to be constrained to the tangible elements of the site.

\begin{tabular}{|l|l|l|l|l|}
\hline Company Role & \multicolumn{2}{|l|}{$\begin{array}{l}\text { Site Visit Interviews } \\
\text { Number of employees }\end{array}$} & \multicolumn{2}{l|}{$\begin{array}{l}\text { Follow up Interviews } \\
\text { Number of Employees }\end{array}$} \\
\hline & Male & Female & Male & Female \\
\hline Company Management & 3 & - & - & - \\
\hline Brewery Operatives & 12 & 2 & 2 & - \\
\hline Administration Staff & - & 4 & - & 3 \\
\hline Building Maintenance & - & - & 2 & - \\
\hline Total & 15 & 6 & 4 & 3 \\
\hline & \multicolumn{2}{|c|}{21} & \multicolumn{2}{|c|}{} \\
\hline
\end{tabular}

Table 2: Intangible Data - Interview Participants

During the ongoing development of the HBIM, a small focus group session was held with stakeholders including researchers, former employees and representatives of the facilities management team of the new owners (Table 3). The purpose of the focus group was to discuss the presentation of the HBIM model and the approaches used to combine tangible and intangible heritage data, identifying the most appropriate way to document the intangible data in relation to the geometric model. A focus group was identified as the most appropriate way to elicit thoughts from the range of stakeholders involved in the 
creation and potential use of the HBIM. Moderated by a member of the CoP, the focus group approach gathered feedback and the allowed ideas for linking tangible and intangible data and potential uses of the HBIM to be explored within a social context (Breen, 2006). Liang et al. (2018) noted that a focus group allowed participants to react and or be inspired by others and this was deemed beneficial as the diverse range of knowledge both about the technical BIM aspects and the knowledge of the building, would provide a rich set of information. The results of the focus group were recorded, and key actions were identified which then fed into the ongoing development of the overall HBIM.

\begin{tabular}{|l|l|l|l|}
\hline $\begin{array}{l}\text { Focus Group } \\
\text { member }\end{array}$ & Background & $\begin{array}{l}\text { Experience of } \\
\text { BIM/HBIM }\end{array}$ & Justification for Inclusion \\
\hline 1 & BIM Researcher & Y & Knowledge of HBIM Development \\
\hline 2 & BIM Researcher & Y & Knowledge of HBIM Development \\
\hline 3 & Estates Management & Y & Potential future user of HBIM \\
\hline 4 & $\begin{array}{l}\text { Brewery } \\
\text { Administration }\end{array}$ & N & $\begin{array}{l}\text { Knowledge of the office areas of the } \\
\text { building }\end{array}$ \\
\hline 5 & Brewery Operative & N & $\begin{array}{l}\text { Knowledge of the building layouts and } \\
\text { working practices }\end{array}$ \\
\hline 6 & Brewery Operative & N & $\begin{array}{l}\text { Knowledge of the building layouts and } \\
\text { working practices }\end{array}$ \\
\hline
\end{tabular}

Table 3: Focus Group Participants

The focus of the research implementation was the 12-acre Springfield site is located towards the North East of the City of Wolverhampton in the UK. The site was originally bought in 1873 by William Butler to house his growing brewing business, with the initial Springfield Brewery opening in 1874 . Occupying one of the largest single sites in the town, during the 1880's (Figure 2), the brewery underwent a large expansion programme and a range of new buildings were added to the site. These new buildings supported the increasing operational capacity, utilising the natural spring water available from the location and making use of the main line rail network adjacent to the site. The brewery functioned successfully until its eventual closer in 1991, when the buildings were mothballed and left to fall into disrepair (Parker, ND). During this period, buildings on the site were listed as Grade 2 by 
Historic England, noting the historic value to the City and its culture (Historic England, 1991). From an architectural perspective, the buildings themselves were visually reminiscent of a wider number of brewery buildings constructed in the late Victorian era (Pearson, 1999). A range of interconnecting buildings made of up several high-level blocks, which included numerous decorative features, whilst the buildings also made use of cast iron frame and Staffordshire Blue Brick (Historic England, 1991). The buildings themselves demonstrate a range of architectural styles relating to the eras of construction including large arched windows and Flemish bond brickwork. From an urban perspective, the site was key to the development of the town as it was one of the largest employers during the early era and historically became a social focus for the town with the inclusion of social clubs and the location of a news journal for all employees. The site also became the location of a town war memorial following the first World War (Parker, ND). 


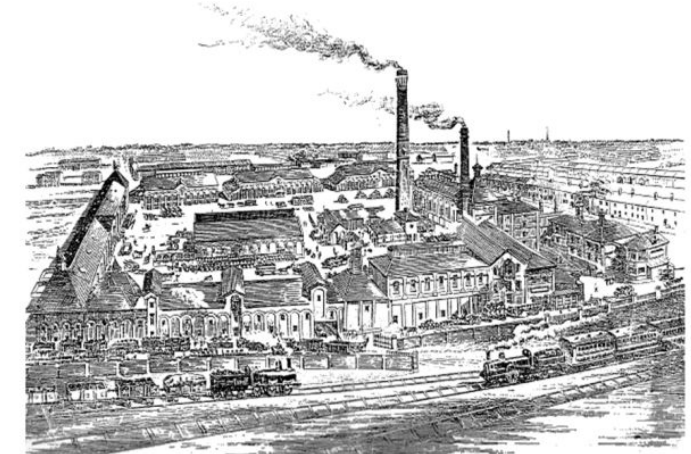

a) Date: 1889

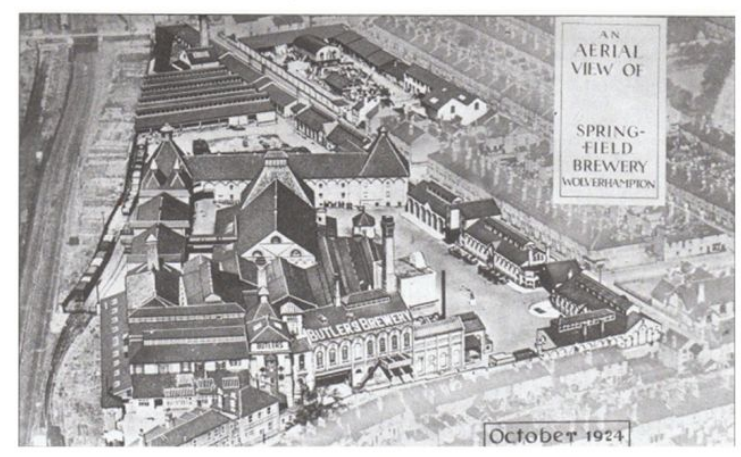

c) Date: 1924

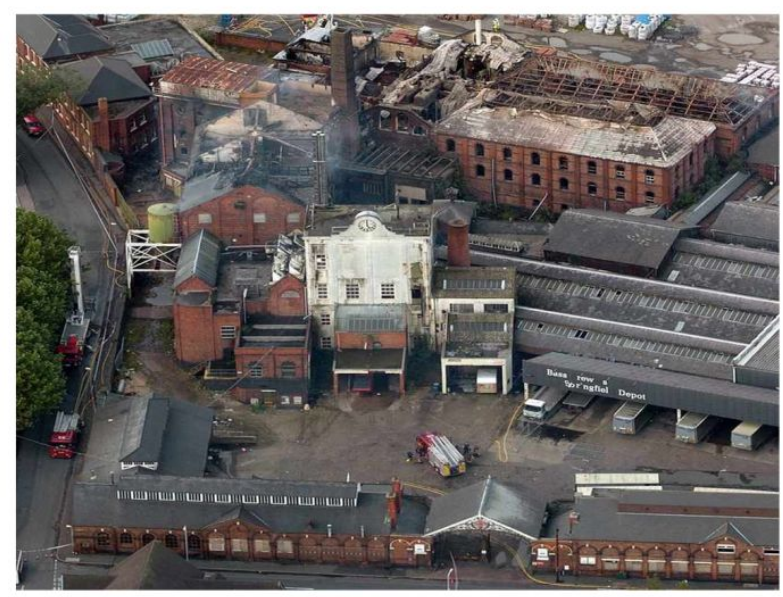

e) Date: 2004

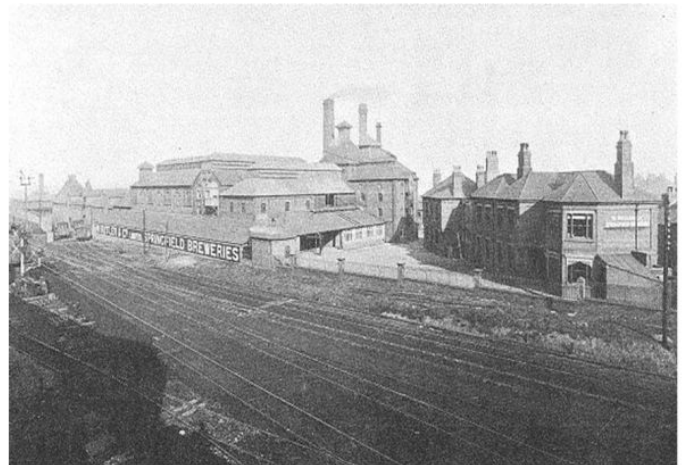

b) Date: 1899

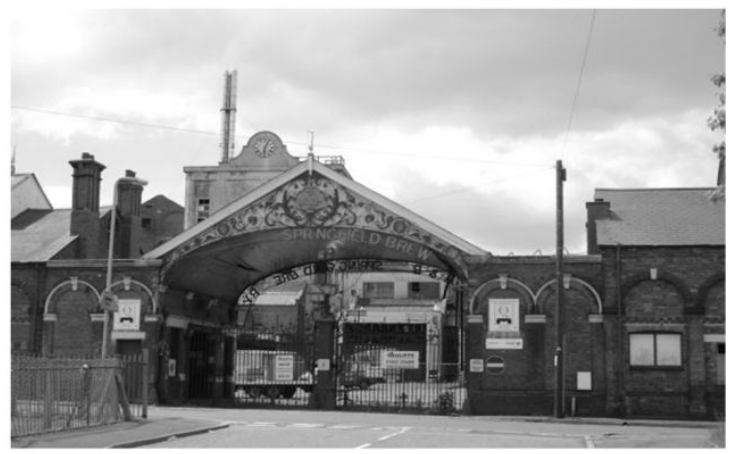

d) Date: Circa 1990

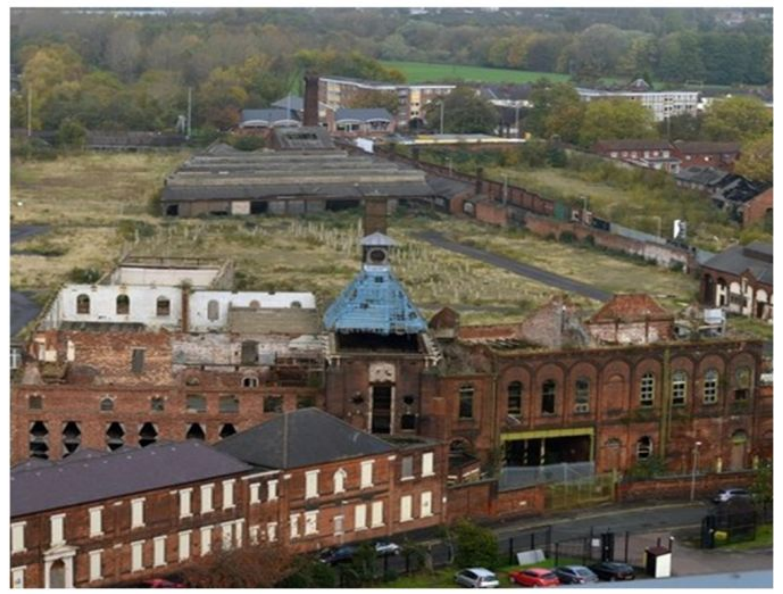

f) Date: 2017

Figure 2: Historical developments of the Springfield site

(Sources: a,b,c) Parker, ND; d) Arnold, 2006; e) Express and Star, 2015; f) Brennan, 2017)

After its closure the site was allocated as a conservation area for the City, however in 2004 a fire destroyed several of the buildings and left others structurally unstable (Express and Star, 2015). A further fire in 2005 damaged more of the site, leaving many of the buildings unrecognisable and led to 
the controlled demolition of some elements of the site. As the buildings fall further into disrepair and in order to support future renovation and adaption, the creation of a HBIM including tangible and intangible heritage information will support future design, construction and operation. Specifically, the HBIM can used by the design and construction team to ensure any renovation and conservation works were undertaken with due regard for any relevant intangible cultural heritage.

\section{Project Implementation}

Based on the research methodology presented above, this work implemented a collaborative BIM process to develop a HBIM that contained both tangible and intangible cultural heritage data.

\subsection{Developing a Heritage BIM Execution Plan (HBEP)}

In order to support the development of a HBIM undertaken using a collaborative approach, this study proposed the development of a HBEP to manage the process and ensure consistency. Initially, an outline framework was developed based on secondary research and the experiences of the CoP. This drew reference from the range of BIM Execution Plans (BEPs) which follow similar approaches to that generated from Penn State University (McArthur and Sun, 2015). Whilst the documents vary for each project, key themes emerge in each of the templates relating to; the development, detail and structure of the 3D geometric model, the amount of information/data attached to the 3D model, the management of the project and the technology to be used in the delivery of the project. Drawing on previous knowledge and the CoP established for the study, a framework was developed to support the creation of a HBEP (Figure 3). 
Figure 3: Framework for HBEP development

\subsubsection{HBEP: Project Management Information}

The key function of the HBEP is to provide a consistent platform for the development of a collaborative HBIM. A specific set of data is required for the management of the project and to ensure all those engaged in the development are operating to the same standards. The 'HBIM project aim' will identify the strategic requirement for the project and the client need. The 'location' of the project will require the HBEP to specify the geographic location of the project. In addition, this aspect of the HBEP will also require a 'coordinate system' to be established for the project such that collaborators in the development can ensure that when any individual HBIM are federated to a single model database they are spatially correct.

A further critical element of the development of the HBIM is the specification of a date (or date range) of the model being developed. Stefani et al (2010) highlighted that heritage assets will often have existed in numerous different states throughout the lifecycle due to creation, destruction, union, division 
etc. When generating or gathering both tangible and intangible heritage data for inclusion in a HBIM, this aspect can significantly affect the geometric modelling. Within the date range, the HBEP could refer to 4D HBIM, which could elucidate the change in the building over time. Furthermore, the it is postulated that 4D HBIM could be either Macro or Micro level. From the perspective of tangible HBIM, macro 4D HBIM can relate to changes to the entire building or urban fabric, which may include demolition and reconstruction of new buildings on an existing site. Micro 4D HBIM relates further to specific individual changes to the building fabric, for example the additional or removal of specific architectural feature such as a door or window. Whilst not directly implemented in this study, the aspect of $4 \mathrm{D}$ HBIM is an area for future research and would also need to include the ability to extend the temporal based concept to intangible data such that any intangible information could be related to a specific point in time.

\subsubsection{HBEP: Tangible Cultural Heritage}

Donato and Biagini (2016) developed a framework for specifying the LOD of heritage buildings based on the AIA specification (AIA, 2013). Further Biagini et al. (2016) implemented the AIA approach for specifying the LOD of geometric objects, producing a model aligned to LOD300. However, these do not align with the geometric properties of many heritage buildings and subsequently Andrews et al. (2015) specify 4 grades of geometric detail when producing models of heritage buildings ranging from Level 1 providing a Basic Outline to Level 4, which presents detailed architectural models. Whilst all of these LOD definitions are useful, there is still a range of subjectivity when producing HBIM and this needs to be accounted for and specified in the HBEP.

The structure of the geometry is a critical aspect of a HBIM, particularly when the project is being developed as part of a collaborative team. Naming conventions used to identify individual specific elements within a BIM are well documented and can take several forms. In the UK naming conventions are based on the BS1192: 2007 document in combination with the Unified Classification for 
Construction Industry (Uniclass) to generate human and machine-readable identifiers. Within the HBEP the naming convention is identified for the project and this can also be used to form a linking mechanism for intangible data. Limited standardised information exists for the naming of BIM objects within a HBIM context and so it was proposed to implement the standard contained with BS1192: 2007.

\subsubsection{HBEP: Intangible Cultural Heritage}

Within the UK Level 2 BIM process, the Level of Information (LOI) refers to the amount of nongraphical (attribute) information attached to graphical objects within the model. Donato et al. (2017) discuss a possible framework for which includes LOI for HBIM and how this can be used to attach appropriate historical information to geometric objects in the model. Specifically the initial prototype framework discussed in the study (ibid), develops the concept of categorising information according to; who, what, when, where and why. This approach serves to provide some discussion on how this data could be stored and in a database format, which could be searched using database query techniques. However, LOI in this case is focused on the typology of the architectural structure rather than the intangible heritage aligned to the model.

\section{Defining a Level of Intangible Cultural Heritage}

Categorising intangible heritage is a difficult task as it is fluid by its very nature and constantly evolving (Cang, 2007). Building on previous research, which identified published information and participatory social media to obtain heritage information, this work initially sought to develop a method to specify and categorise a Level of Intangible Cultural Heritage (LOICH) into 3 classifications.

- LOICH1 - Desk Study/Published information

- LOICH2 - First Person accounts

- LOICH3 - Interactive Social Media 
Using the definitions from UNESCO (2003) each of these Levels could contain more specific information on the type of intangible heritage ranging from oral traditions to skills. Noting the fluidity of these, a further classification could be added to the LOICH to determine the specific origin of typology of the intangible information (Figure 4). In addition to providing a common framework for the generation and documentation of LOICH within the HBIM, the above can also be used to ensure a standardised naming convention is applied to all elements of intangible data within the project.

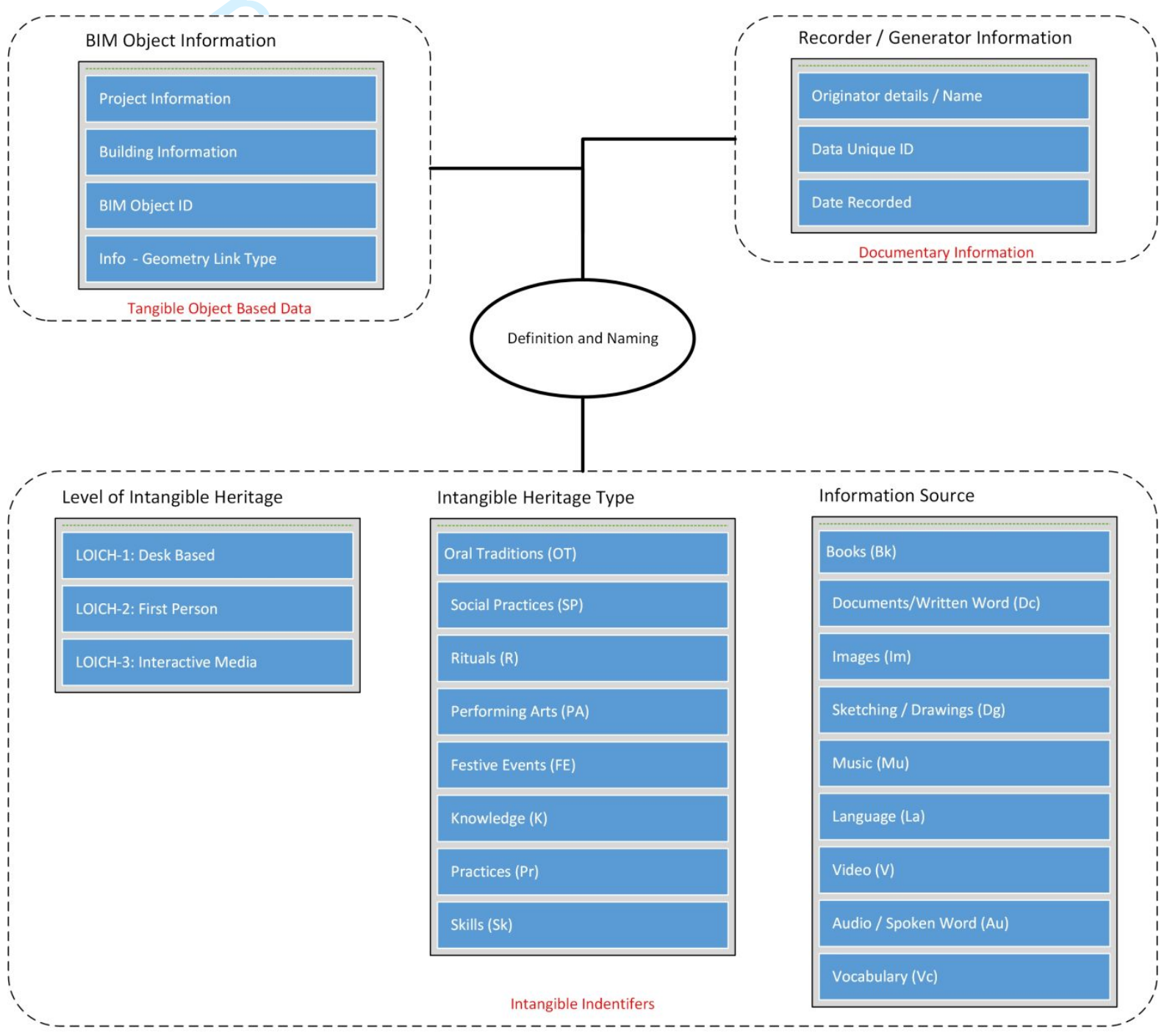

Figure 4: LOICH definition framework and naming convention

The overall approach to identifying and naming intangible heritage data, drew inspiration from the current processes identified in BS1192 (BSI, 2015). By adopting a similar approach, a level of 
consistency can be maintained across both tangible and intangible aspects of the HBIM and can also support a more standardised naming convention for all digital data (both tangible and intangible) stored in the Common Data Environment (CDE). Furthermore, it should be noted that intangible data can be aligned to various aspects of the geometric BIM dataset and so this features in the naming convention. To support the naming of intangible heritage data digital containers and storage in the CDE, a digital toolkit was implemented (Figure 5) based on the definition framework above. This allowed naming to be consistent across the collaborative project and could then also be used during the linking process to geometric elements of the BIM through the CDE

\section{Intangible Heritage BIM Naming Generator}

\begin{tabular}{|c|c|}
\hline Project Number / Name & Springfield \\
\hline BIM Geometric Object & Room Level \\
\hline \multicolumn{2}{|l|}{ BIM Object ID } \\
\hline LOICH & First Person \\
\hline Intangible Heritage Type & Rituals \\
\hline Information Source & Audio / Spoken Word \\
\hline Originator Name & DTH \\
\hline Unique ID & 0001 \\
\hline Date recorded & $01 / 12 / 2017$ \\
\hline Intangible Object Name & Springfield-RL-zz-LOICH-2-R-Au-DTH-0001-01/12/2017 \\
\hline
\end{tabular}

Figure 5: Intangible Heritage Container Naming Toolkit

The quality assessment of the intangible information is also something that requires attention during the HBIM development. This is an area of future research, but should include a method to semantically categorise the quality of the intangible data gathered as part of the BIM process. This will provide the ability to give a confidence level to the information provided to the user of the HBIM. 


\subsection{Implementing a CDE for Tangible and Intangible BIM data}

Aligning to current BIM processes and supporting the collaborative development of a HBIM, a CDE should be implemented to hold all the tangible data and either contain, or collate, links to intangible heritage data. Donato et al. (2018) noted the potential of web based portals to also hold intangible data which could be linked to geometric virtual objects in the model. A CDE was implemented using the principles set down in BS1192: 2007 but extended to suit a HBIM application. Using Autodesk A360, the structure of the CDE project folder was divided into Tangible Heritage and Intangible Heritage, with subsequent sub folders for each building within the project (Figure 6).

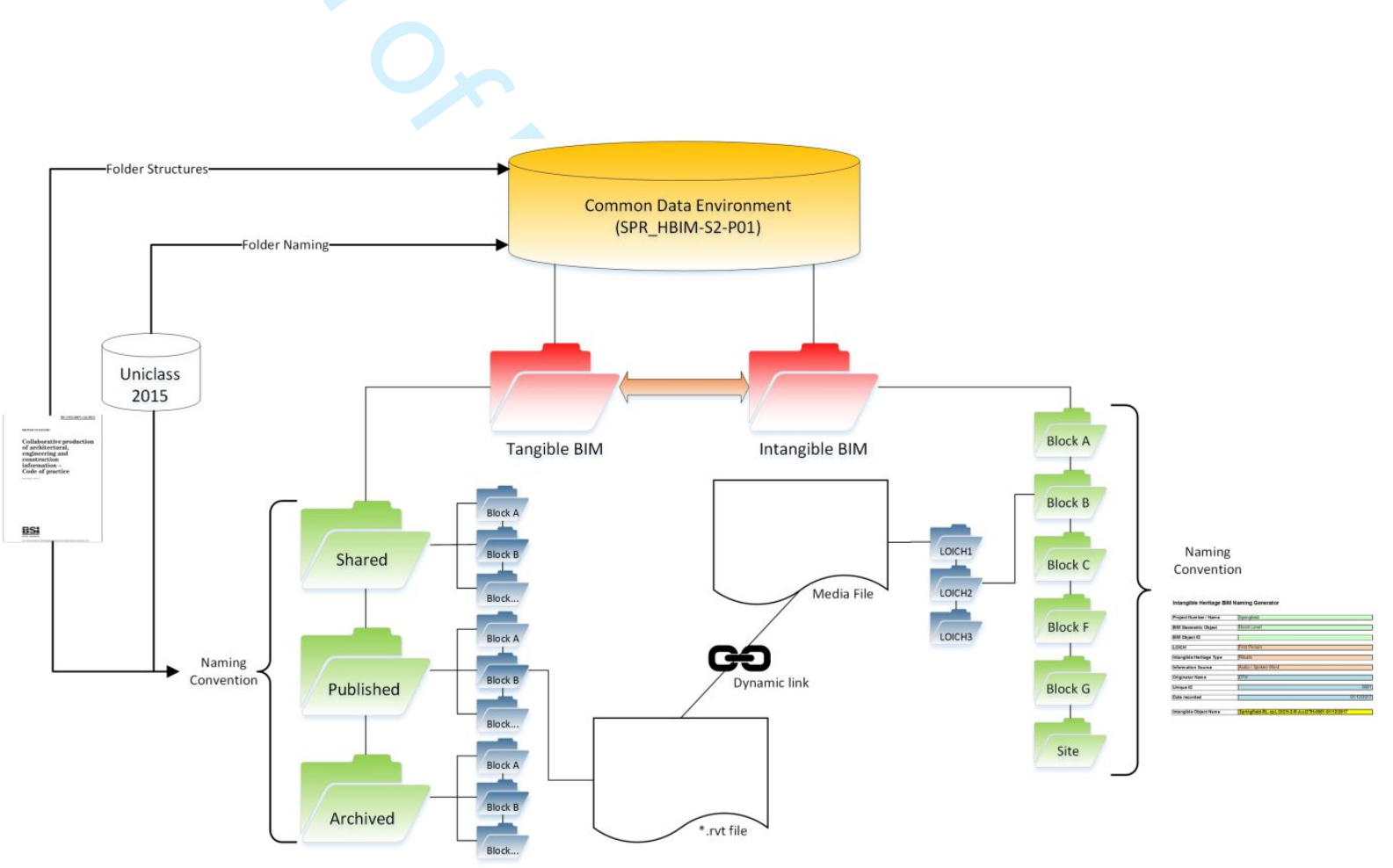

Figure 6: Structuring a CDE for HBIM

The naming convention for the tangible and intangible containers followed BS1192:2007, and the structure of tangible data included Shared, Published and Archived folders, which were populated as the project progressed. In addition, the naming convention of the folder containers, and the files, implemented Uniclass 2015 for tangible data, whilst the approach discussed previously for the naming of intangible data was implemented. 


\subsection{Implementing Tangible HBIM}

Autodesk Revit was selected as the tool to support the generation of the tangible HBIM. This tool is the most prolific BIM authoring tool in the UK at the present time (NBS, 2017) and is also extensively used in previous research focusing on HBIM. The project involved the creation of 5 individual models of buildings across the site. In accordance with the developed HBEP, and using the LOD specification set out by Heritage England, each building and subsequent elements were generated to LOD 3 noting that 'outline of the building/structure represented as a solid object with all architectural features and major service detail included using generic components' (Andrews et al., 2015). In addition, each modeled element had a Revit Shared Parameter entitled 'Tangible LOD'. This defaulted to state LOD3, however if more detail could be added, or not enough data was available this was changed to allow a future audit to be undertaken of objects within the model.

An initial full 3D laser scan was obtained for the site based on the 2016 condition of the dilapidated buildings and this was supplemented by additional drone surveys undertaken to capture further internal details. The laser scan data contained a full range of measurement data providing a minimum of $6 \mathrm{~mm}$ point spacing which provided an initial backdrop for geometric modelling. The modelling process from laser scan (Figure 7) followed the processes highlighted in published scan to BIM projects. This established workflow for the creation of heritage BIM has been proven in previous studies. (Laing et al., 2015; Apollonio et al., 2017; Lopez et al., 2017). 


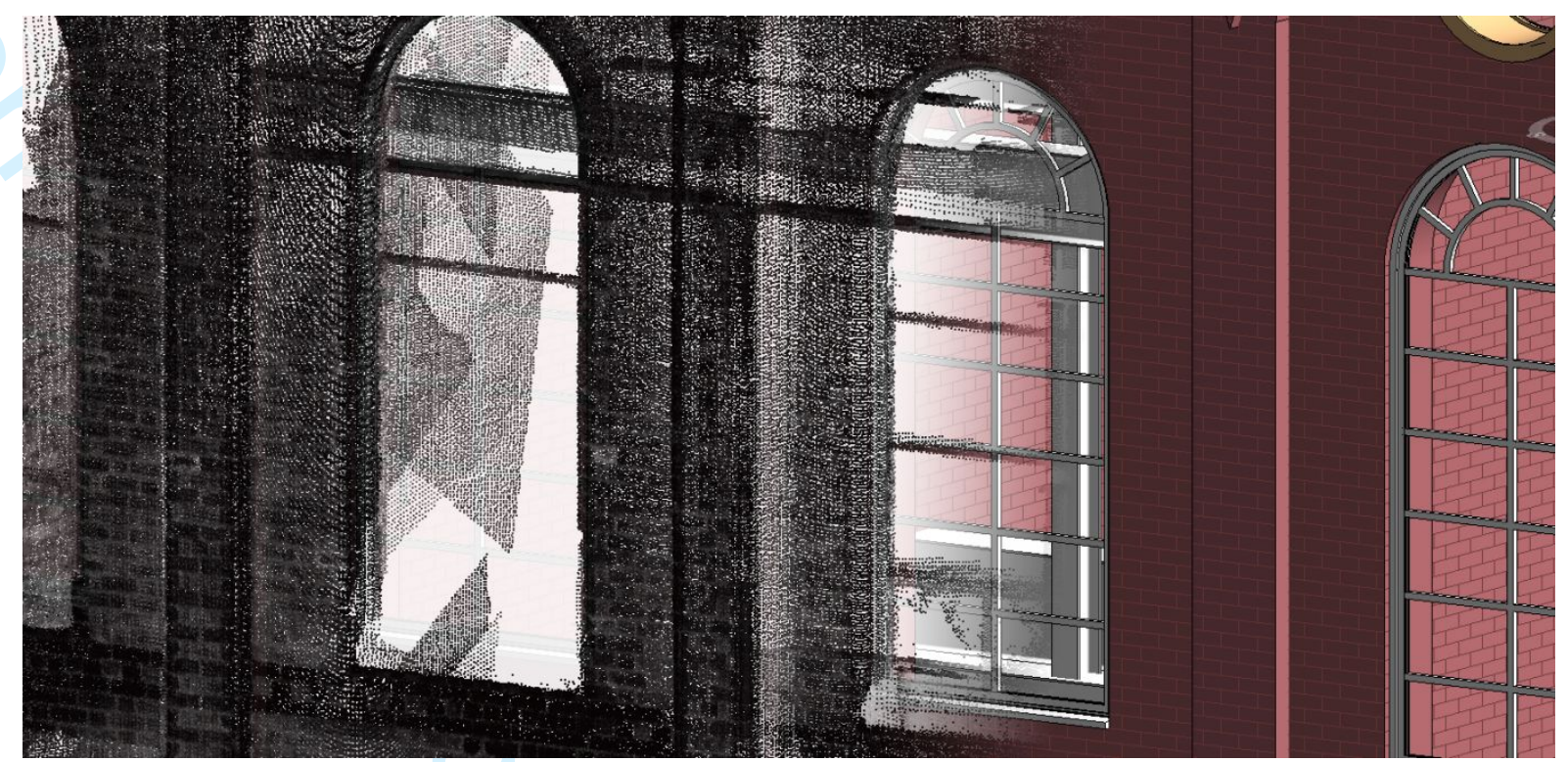

Figure 7: Using Scan to BIM methodologies for geometric modelling existing building

Due to the degraded nature of the buildings and in order to develop full geometric models further research was undertaken to supplement the laser scan data. Regional and national archives were searched to find a wide range of information, which could support the modelling process. Architectural plans and photographs, specifically showing the architecture of the buildings from the specified era, were able to show some features which could then be used during the modelling process. This element of the research process also identified a specific building which no longer existed (Boiler building no.1) which was added to the site in the 1920 's to meet expanding production on the site but had been completely destroyed (Figure 8). Using this data, a 3D model was generated showing the detailed construction and structure of the building fabric. 

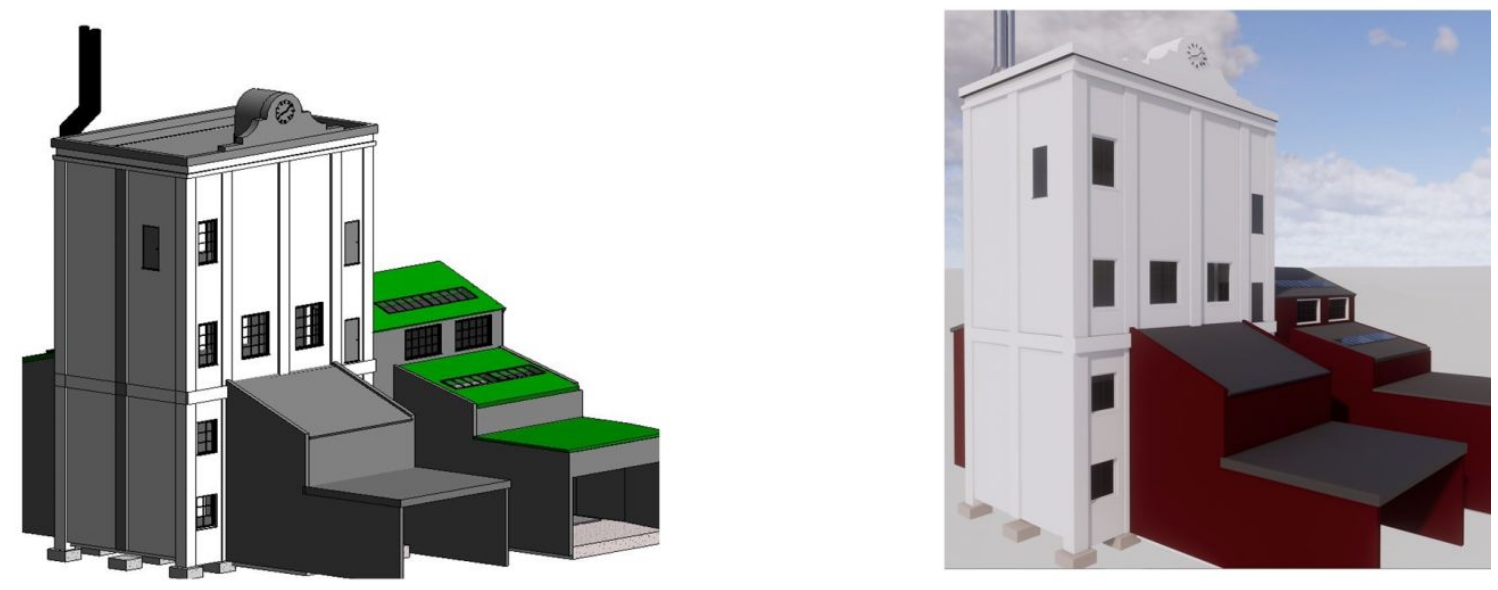

Figure 8: Boiler House no.1 demolished due to 2004 fire damage created from planning drawings and photographs

\subsection{Implementing Intangible data into HBIM}

In order to capture intangible heritage data of the site whilst it was operational, a multi-faceted approach was taken to data collection. In order to provide a base Level of Intangible Cultural Heritage (LOICH1), a thorough desk study was undertaken of the history of the site including written accounts of working practices, photographs and documents related to the operation of the building. It is recognised that photographs could also be classified as contributing to the creation of tangible/geometric modelling. However, for the purposes of this study they were also deemed as sources of intangible data. During its operation, the site was one of the largest employers within the City and often several generations would spend their entire working lives employed on the site. The working conditions, and nature of the buildings, provided a range of intangible heritage, such as specific working practices, rituals and social 
practices. Initially, a six-month data collection exercise was undertaken by members of the CoP, capturing a range of intangible data about the site. Each piece was documented, named and stored in the CDE as described in the HBEP.

In order to further develop the level of intangible data and create LOICH2 for the project, a qualitative data collection approach was implemented as discussed previously. The unstructured interviews provided participants with the opportunity to discuss all aspects of the building, its structure, operation, the practices and the impact on the community (Labhart, 2017). The data was audio and video recorded and the files were thematically analysed and categorised based on which building or part of the site was being discussed and which Intangible Heritage Type the information aligned to. The files were then divided into smaller media-bites and stories based on the location.

If these aspects of intangible data were connected to a building or the site, markers were used as place holders to link the intangible data to the 3D geometric model (Figure 9). This concept is adapted from the development of semantic information based 'totems' (Pärn and Edwards, 2017), which provide the ability to geolocate information not connected to a specific geometric element within a BIM environment. Whilst this previous work focused on COBie data and allowed the user to input data via an API, the approach here utilised shared parameters to link to the external database held within the CDE. Where data could be attributed to room objects created in the BIM authoring software or individual geometric objects, Shared Parameters were generated and linked to each object within the Revit file, ensuring consistency. 

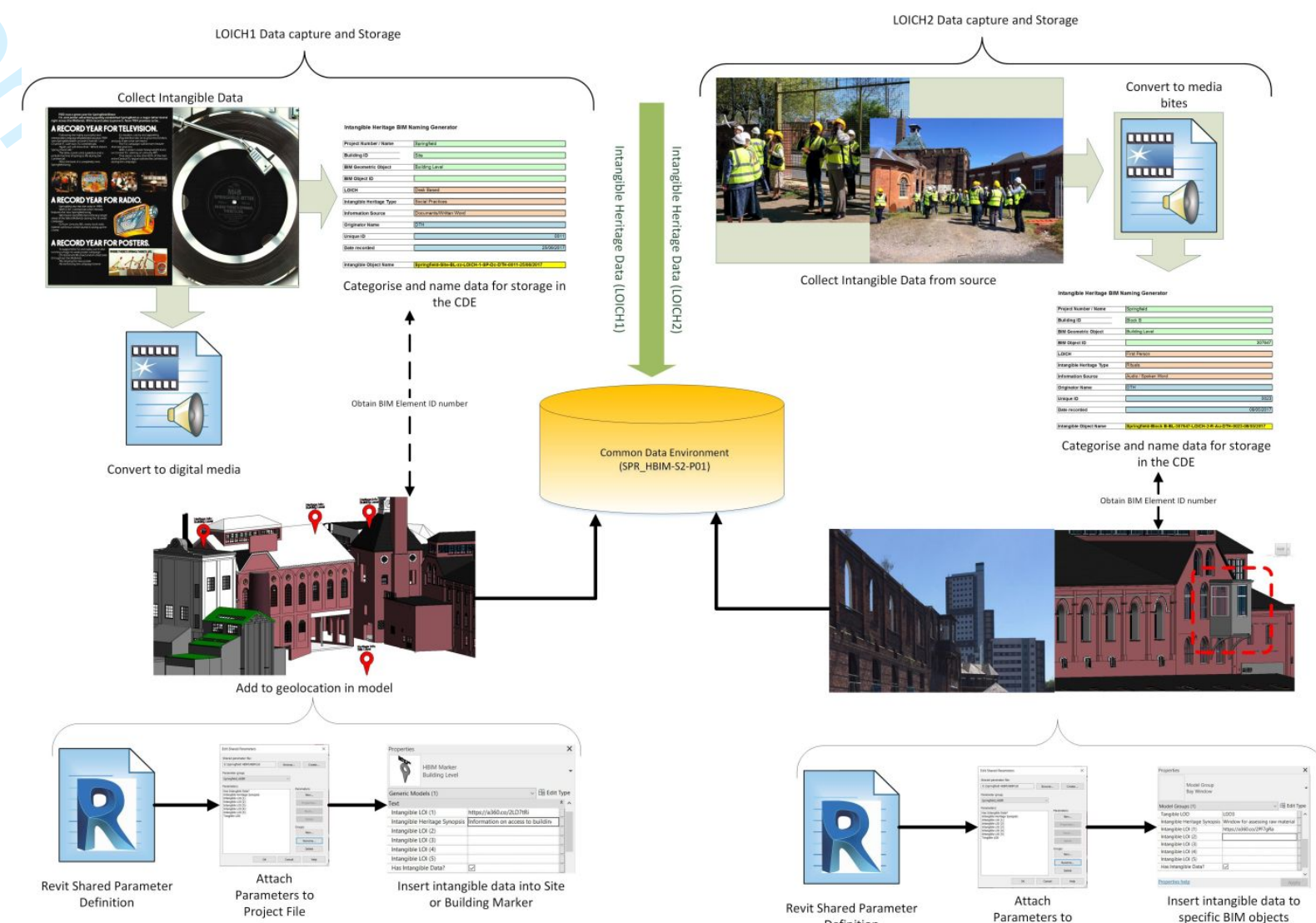

Figure 9: Creating links between Tangible and Intangible data within the HBIM

In order to develop the link between the tangible and intangible data, the shared parameter facility within Autodesk Revit was utilised (Figure 9). This methodology allowed for an extensible template file to be created which can be reused on other HBIM projects. The individual shared parameters were then attached to the project files and specifically the full range of object types within the Revit file. Initially a Boolean based parameter was implemented to detect whether the object had intangible data attached. This could then be used in downstream visualisation activities to highlight which objects contained intangible heritage information. In addition, further text-based parameters held information relating to a brief synopsis of any intangible data and the LOD used for the geometric modelling. URL based parameters were implemented to hold a hyperlink to the intangible data stored on the CDE. 


\subsection{HBIM Presentation Mechanism}

For the purpose of this study, the approach taken was to retain the ability to visualise the tangible and intangible data within the ecosystem of traditional BIM software tools. As such Autodesk Navisworks was implemented as the method to view the tangible and intangible heritage BIM data through a visual interface. As the software tool provides the ability to view and interrogate non-graphical data within the BIM database, it provides opportunity to access the intangible data through a geometric interface. In order to undertake this aspect, the BIM data was analysed using the parameters attached to objects in the BIM authoring tool. Using the parameter-based search tools within Navisworks, all objects that had intangible data attached were selected and highlighted to differentiate them from other objects. Using a freely available add-in tool (Properties+) a specific dialogue tool was implemented to show only the intangible heritage data parameters when objects were selected or 'clicked'. This presented the user with hyperlinks to intangible data stored in the CDE, which was then launched in a new window to allow viewing of the information (Figure 10). 
Figure 10: Visualising HBIM data within Autodesk Navisworks

\section{Discussion and Future work}

The study reported in this paper has implemented a collaborative based approach to develop a large scale HBIM that bought together tangible and intangible heritage information. The ability to bring together this full set of data surrounding a building could have significant consequences during any renovation work undertaken during an adaption project. It can be seen from the review of literature that much of the work relating to HBIM is focused on the technical development of models, and these often report on the variative methods of modelling from laser scan data. Furthermore, many of the previous studies report on the modelling of individual buildings or assets. This study went beyond this technical approach to implement a collaborative process, aligned to the Level 2 BIM process to develop a full HBIM incorporating tangible and intangible data. The definition of intangible heritage data, according 
to UNESCO, is very board and so a level of flexibility is required to ensure the BIM data sets can incorporate this. Very often HBIM will be required on projects where renovation works are due to take place. In these cases, the value of the intangible data can be significant to both the design, construction and facilities management teams. For the design teams it can give insight into the historic design philosophy of the building and as such provide guidance to future interventions. For the construction and asset management teams any intangible data can identify historic significance of elements of the building which can influence construction methods and future maintenance schedules.

The use of a Common Data Environment to hold all information provides a scalable and flexible approach for the management of data. Intangible heritage data is not something that has been formalised in the context of HBIM generation, and this work has sought to bring about a broad structure to allow this to be categorised. The development of the LOICH can be viewed as a parallel stream to the current Level of Information for non-heritage BIM. Whilst it is acknowledged that this is a first step into providing a definition, future work can help to further categorise this into a more robust approach to identify and categorise intangible data. The issue relating to quality of intangible data sources can be further explored aligned to opportunities for linking social media-based data into the HBIM for live and on-going capture of intangible heritage data.

Successful digitization of cultural heritage information in HBIM requires a standard information format, which is represented in the Industry Foundation Classes (IFC) for BIM. Current IFC format requires expansion to incorporate quantitative and qualitative assets including connecting tangible and intangible data and this is also an area of future research.

\section{Conclusions}

Existing literature demonstrates that within the BIM paradigm, Heritage BIM is a dedicated research area that has gained substantial traction since the term was first used in in the first decade of the twenty- 
The project reported in this paper implemented a multi method research methodology to develop a distinct approach to the production of a HBIM. By undertaking the development of a HBIM of a multi building, historic industrial site, a collaborative approach was undertaken and led to the development of a neoteric HBEP which drew on knowledge from prevailing research and the knowledge of a Community of Practice. Unlike more conventional BEP, the HBEP identified the need for both tangible and intangible heritage data, and presented a method to structure this within a HBEP document. Building on the intangible aspect of the data, the work proposed a method to define and categorise intangible data within a BIM approach. The introduction of the concept of Level of Intangible Cultural Heritage (LOICH) and an approach to implement a CDE to underpin the collaborative HBIM development was key to this element. The development of tangible geometric data followed a well described approach, however the collection of qualitative intangible data involved both interview and focus groups methodologies. The data was then combined through the CDE to provide a holistic HBIM, which can now be used by designers, contractors and the asset management team during the renovation works undertaken on the site. 


\section{Acknowledgements}

The Authors would like to acknowledge the University of Wolverhampton for access to the Springfield Development site. Acknowledgement also goes to the members of the Springfield Pensions Group who actively participated in this project for the development of Intangible Heritage Information. The Authors are also very grateful to the cohorts of Postgraduate BIM students who supported the generation of tangible heritage aspects of the project through the 3D modelling of the buildings.

\section{References:}

- AHMAD, Y., 2006. The scope and definitions of heritage: from tangible to intangible. International journal of heritage studies, 12(3), pp. 292-300.

- ANDREWS, D., BEDFORD, J. and BRYAN, P., 2015. Metric Survey Specifications for Cultural Heritage. 3rd edn. Swindon, UK: Historic England.

- ANTONOPOULOU, S. and BRYAN, P., 2017. BIM for Heritage - Developing a Historic Building Information Model. Swindon, UK: Historic England.

- APOLlONIO, F.I., GAIANI, M. and SUN, Z., 2017. A Reality Integrated BIM for Architectural Heritage Conservation. Handbook of Research on Emerging Technologies for Architectural and Archaeological Heritage. IGI Global, pp. 31-65.

- APOLLONIO, F.I., GAIANI, M. and SUN, Z., 2012. BIM-based modeling and data enrichment of classical architectural buildings. SCIRES-IT: SCIentific RESearch and Information Technology, 2(2), pp. 41-62.

- ARNOLD, L., June 24, 2006-last update, Springfield Brewery Wolverhampton. Available: http://www.larry-arnold.net/photography/Wolverhampton/index.htm [January 10, 2018].

- BAIK, A., YAAGOUBI, R. and BOEHM, J., 2015. Integration of Jeddah historical BIM and 3D GIS for documentation and restoration of historical monument. The International Archives of Photogrammetry, Remote Sensing and Spatial Information Sciences, 40(5), pp. 29.

- BAIK, A. and BOEHM, J., 2015. Building information modelling for historical building Historic Jeddah-Saudi Arabia, Digital Heritage, 2015 2015, IEEE, pp. 125-128.

- BIAGINI, C., CAPONE, P., DONATO, V. and FACCHINI, N., 2016. Towards the BIM implementation for historical building restoration sites. Automation in Construction, 71, pp. 74-86.

- BIMForum, 2017 Level of Development Specification. Available: http://bimforum.org/wpcontent/uploads/2017/11/LOD-Spec-2017-Part-I-2017-11-07-1.pdf [January 2018]. 
- BREEN, R.L., 2006. A practical guide to focus-group research. Journal of Geography in Higher Education, 30(3), pp.463-475.

- BREGIANNI, A., 2013. BIM Development for Cultural Heritage Management. National Technical University of Athens School of Rural \& Surveying Engineering Lab of Photogrammetry et Politecnico di Milano School of Architecture BEST Department.

- BRENNAN, M., July 27 2017, 2017-last update, Springfield Brewery transformation cost spirals by $£ 500 \mathrm{k}$

[Homepage of $\quad$ MNA], Anline]. Available: https://www.expressandstar.com/news/2017/07/27/brewery-campus-costs-spiral/ [January 10, 2018].

- CANG, V.G., 2007. Defining intangible cultural heritage and its stakeholders: The case of Japan. International Journal of Intangible Heritage, 2, pp. 45-55.

- COOMBS, J., THOMAS, M., RUSH, N. AND MARTIN, E., 2017. A Community of Practice approach to delivering research support services in a post-92 Higher Education Institution: A reflective case study. New Review of Academic Librarianship, 23(2-3), pp.159-170.

- COUNSELL, J. and TAYLOR, T., 2017. 3W VWhat are the goals of HBIM? Heritage Building Information Modelling,

- DAWOOD, N. AND VUKOVIC, V., 2015. Whole lifecycle information flow underpinned by BIM: technology, process, policy and people. In 2nd International Conference on Civil and Building Engineering Informatics.

- DENSCOMBE, M., 2008. COMMUNITIES OF PRACTICE: A RESEARCH PARADIGM FOR THE MIXED METHODS APPROACH. JOURNAL OF MIXED METHODS RESEARCH, 2(3), PP.270-283.

- DONATO, V. and BIAGINI, C., 2016. Levels of development (LOD) for historic building information modeling (HBIM): towards building simulation.

- DONATO, V., GIANNETTI, S. and BOCCONCINO, M.M., 2018. H-BIM and web-database to deal with the loss of information due to catastrophic events.

- DORE, C. and MURPHY, M., 2012. Integration of Historic Building Information Modeling (HBIM) and 3D GIS for recording and managing cultural heritage sites, Virtual Systems and Multimedia (VSMM), 2012 18th International Conference on 2012, IEEE, pp. 369-376.

- DORE, C., MURPHY, M., MCCARTHY, S., BRECHIN, F., CASIDY, C. and DIRIX, E., 2015. Structural simulations and conservation analysis-historic building information model (HBIM). The International Archives of Photogrammetry, Remote Sensing and Spatial Information Sciences, 40(5), pp. 351.

- DWAIRI, S. and MAHDJOUBI, L., 2017. 18W Development of OntEIR framework to support heritage clients. Heritage Building Information Modelling, . 
- DWAIRI, S., MAHJOUBI, L., ODEH, M. and KOSSMANN, M., 2017. Ont-EIR framework to deliver sustainable heritage projects. Advanced Technologies for Sustainable Systems. Springer, pp. 19-30.

- EASTMAN, C.M., EASTMAN, C., TEICHOLZ, P. and SACKS, R., 2011. BIM handbook: A guide to building information modeling for owners, managers, designers, engineers and contractors. John Wiley \& Sons.

- EDWARDS, J., 2017. It's BIM-but not as we know it! Heritage Building Information Modelling. Routledge, pp. 6-14.

- ETIKAN, I., MUSA, S.A. AND ALKASSIM, R.S., 2016. Comparison of convenience sampling and purposive sampling. American journal of theoretical and applied statistics, 5(1), pp.1-4.

- EXPRESS AND STAR, 1st October 2015, 2015-last update, Flashback: 2004 blaze ravages Springfield Brewery [Homepage of MNA], [Online]. Available: https://www.expressandstar.com/news/2015/10/01/flashback-2004-blaze-ravages-springfieldbrewery/ [January 10, 2018].

- FAI, S., GRAHAM, K., DUCKWORTH, T., WOOD, N. and ATTAR, R., 2011. Building information modelling and heritage documentation, Proceedings of the 23rd International Symposium, International Scientific Committee for Documentation of Cultural Heritage (CIPA), Prague, Czech Republic 2011, pp. 12-16.

- FAI, S. and SYDOR, M., 2013. Building Information Modelling and the documentation of architectural heritage: Between the 'typical'and the 'specific', Digital Heritage International Congress (DigitalHeritage), 2013 2013, IEEE, pp. 731-734.

- FASSi, F., MANDElli, A., TERUGGI, S., RECHICHI, F., FIORILlO, F. and ACHILle, C., 2016. VR for Cultural Heritage, International Conference on Augmented Reality, Virtual Reality and Computer Graphics 2016, Springer, pp. 139-157.

- FOLWELL, P., 2015-last update, Heritage and BIM. Available: https://aecmag.com/case-studiesmainmenu-37/942-heritage-and-bim [Januray, 2018].

- GARAGNANI, S., 2015. Semantic representation of accurate surveys for the cultural heritage: BIM applied to the existing domain. Handbook of Research on Emerging Digital Tools for Architectural Surveying, Modeling, and Representation, 1, pp. 299-317.

- GRAY, D.E., 2013. Doing research in the real world. Sage.

- HISTORIC, E., 2018. 3D Laser Scanning for Heritage: Advice and Guidance on the Use of Laser Scanning in Archaeology and Architecture. 2nd edn. Swindon, UK: Historic England.

- JAMSHED, S., 2014. Qualitative research method-interviewing and observation. Journal of basic and clinical pharmacy, 5(4), p.87.

- JOKILEHTO, J., 2005. Definition of cultural heritage: References to documents in history. ICCROM Working Group 'Heritage and Society, , pp. 4-8. 
- JORDAN-PALOMAR, I., TZORTZOPOULOS, P., GARCÍA-VALLDECABRES, J. and PELLICER, E., 2018. Protocol to Manage Heritage-Building Interventions Using Heritage Building Information Modelling (HBIM). Sustainability, 10(4), pp. 908.

- KEARNEY, A., 2008. Intangible cultural heritage. Intangible heritage, , pp. 209.

- KHODEIR, L.M., ALY, D. and TAREK, S., 2016. Integrating HBIM (Heritage Building Information Modeling) tools in the application of sustainable retrofitting of heritage buildings in Egypt. Procedia Environmental Sciences, 34, pp. 258-270.

- KURIN, R., 2007. Safeguarding intangible cultural heritage: Key factors in implementing the 2003 Convention. International Journal of Intangible Heritage, 2(8), pp. 9-20.

- LAING, R., LEON, M., ISAACS, J. and GEORGIEV, D., 2015. Scan to BIM: the development of a clear workflow for the incorporation of point clouds within a BIM environment. WIT Transactions on The Built Environment, 149, pp. 279-289.

- LENZERINI, F., 2011. Intangible cultural heritage: The living culture of peoples. European Journal of International Law, 22(1), pp. 101-120.

- LIANG, Q., LEUNG, M.Y. AND COOPER, C., 2018. Focus group study to explore critical factors for managing stress of construction workers. Journal of Construction Engineering and Management, 144(5), p.04018023.

- LIN, Y., LEE, H. and YANG, I., 2016. Developing as-built BIM model process management system for general contractors: a case study. Journal of Civil Engineering and Management, 22(5), pp. 608621.

- LOGOThetis, S., DelinASiOU, A. and STYLiANIDIS, E., 2015. Building information modelling for cultural heritage: a review. ISPRS Annals of the Photogrammetry, Remote Sensing and Spatial Information Sciences, 2(5), pp. 177.

- LOPEZ, R., CHONG, H., WANG, X. and GRAHAM, J., 2015. Technical Review: Analysis and Appraisal of Four-Dimensional Building Information Modeling Usability in Construction and Engineering Projects. Journal of Construction Engineering and Management, , pp. 06015005.

- LÓPEZ, F.J., LERONES, P.M., LLAMAS, J., GÓMEZ-GARCÍA-BERMEJO, J. and ZALAMA, E., 2017. A Framework for Using Point Cloud Data of Heritage Buildings Toward Geometry Modeling in A BIM Context: A Case Study on Santa Maria La Real De Mave Church. International Journal of Architectural Heritage, 11(7), pp. 965-986.

- MARZOUK, M., METAWIEB, M. and ALI, M., 2016. Framework for HBIM Applications in Egyptian Heritage.

- MAXWELL, I., 2014. Integrating Digital Technologies in Support of Historic Building Information Modelling: BIM4Conservation (HBIM)-A Cotac Report.'. Online at: www.cotac.org.uk/docs/COTAC-HBIM-Report-Final-A-21-April-2014-2-small.pdf, . 
- MCARTHUR, J. and SUN, X., 2015. Best practices for BIM Execution Plan development for a Public-Private Partnership Design-Build-Finance-Operate-Maintain Project. WIT Transactions on The Built Environment, 149, pp. 119-130.

- MORRICAL, K., 2017-last update, BIM for Existing Structures: A Discussion. Available: https://medium.com/autodesk-university/bim-for-existing-structures-a-discussion-86bdb29aae4b [January, 2018].

- MORDUE, S., SWADDLE, P. AND PHILP, D., 2015. Building information modeling for dummies. John Wiley \& Sons.

- MURPHY, M., MCGOVERN, E. and PAVIA, S., 2009. Historic building information modelling (HBIM). Structural Survey, 27(4), pp. 311-327.

- NBS, , 2016-last update, NBS BIM Toolkit. Available: https://toolkit.thenbs.com/ [January 2018, 2018].

- OCHMANN, S., VOCK, R., WESSEL, R. AND KLEIN, R., 2016. Automatic reconstruction of parametric building models from indoor point clouds. Computers \& Graphics, 54, pp.94-103.

- ORENI, D., BRUMANA, R., GEORGOPOULOS, A. and CUCA, B., 2013. HBIM for conservation and management of built heritage: Towards a library of vaults and wooden bean floors. ISPRS Annals of Photogrammetry, Remote Sensing and Spatial Information Sciences, 5, pp. W1.

- OSEllo, A., LUCiBEllO, G. and MORGAGNI, F., 2018. HBIM and Virtual Tools: A New Chance to Preserve Architectural Heritage. Buildings, 8(1), pp. 12.

- PARKER, B., ND-last update, Wolverhampton's King of Brewers and his Brewery at Springfield. Available: http://www.historywebsite.co.uk/articles/butlers/brewery.htm [January 1, 2018].

- PÄRN, E.A. AND EDWARDS, D.J., 2017. Conceptualising the FinDD API plug-in: A study of BIM-FM integration. Automation in Construction, 80, pp.11-21.

- PAUWELS, P., BOD, R., DI MASCIO, D. and DE MEYER, R., 2013. Integrating building information modelling and semantic web technologies for the management of built heritage information, Digital Heritage International Congress (DigitalHeritage), 2013 2013, IEEE, pp. 481488.

- POUX, F., NEUVILle, R., HALlOT, P. AND BILlEN, R., 2017. Model for reasoning from semantically rich point cloud data. ISPRS Annals of the Photogrammetry, Remote Sensing and Spatial Information Sciences, 4, pp.107-115.

- PYRKO, I., DÖRFLER, V. AND EDEN, C., 2017. Thinking together: What makes Communities of Practice work?. Human relations, 70(4), pp.389-409.

- SAYGI, G. and REMONDINO, F., 2013. Management of Architectural Heritage Information in BIM and GIS: State-of-the-art and Future Perspectives. International Journal of Heritage in the Digital Era, 2(4), pp. 695-713. 
- SHARIF, M.M., NAHANGI, M., HAAS, C. AND WEST, J., 2017. Automated model-based finding of 3D objects in cluttered construction point cloud models. Computer-Aided Civil and Infrastructure Engineering, 32(11), pp.893-908.

- STEFANI, C., DE LUCA, L., VÉRON, P. and FLORENZANO, M., 2010. Time indeterminacy and spatio-temporal building transformations: an approach for architectural heritage understanding. International Journal on Interactive Design and Manufacturing (IJIDeM), 4(1), pp. 61-74.

- SUCCAR, B., 2009. Building information modelling framework: A research and delivery foundation for industry stakeholders. Automation in construction, 18(3), pp.357-375.

- TANG, P., HUBER, D., AKINCI, B., LIPMAN, R. and LYTLE, A., 2010. Automatic reconstruction of as-built building information models from laser-scanned point clouds: A review of related techniques. Automation in Construction, 19(7), pp. 829-843.

- TOBIAS, P., 2016. BIM, GIS and semantic models of cultural heritage buildings. 15, pp. 27.

- TOMMASI, C., ACHILlE, C. AND FASSI, F., 2016. From point cloud to BIM: a modelling challange in the Cultural Heritage field. INTERNATIONAL ARCHIVES OF THE PHOTOGRAMMETRY, REMOTE SENSING AND SPATIAL INFORMATION SCIENCES, pp.429-436.

- UNESCO, 2003. Convention for the Safeguarding of the Intangible Cultural Heritage.

- VECCO, M., 2010. A definition of cultural heritage: From the tangible to the intangible. Journal of Cultural Heritage, 11(3), pp. 321-324.

- VOLK, R., STENGEL, J. and SCHULTMANN, F., 2014. Building Information Modeling (BIM) for existing buildings-Literature review and future needs. Automation in Construction, 38, pp. 109127.

- WANG, C., CHO, Y.K. AND KIM, C., 2015. Automatic BIM component extraction from point clouds of existing buildings for sustainability applications. Automation in Construction, 56, pp.113.

- XIONG, X., ADAN, A., AKINCI, B. and HUBER, D., 2013. Automatic creation of semantically rich 3D building models from laser scanner data. Automation in Construction, 31, pp. 325-337.

- ZHANG, Y. AND WILDEMUTH, B.M., 2009. Unstructured interviews. Applications of social research methods to questions in information and library science, pp.222-231. 


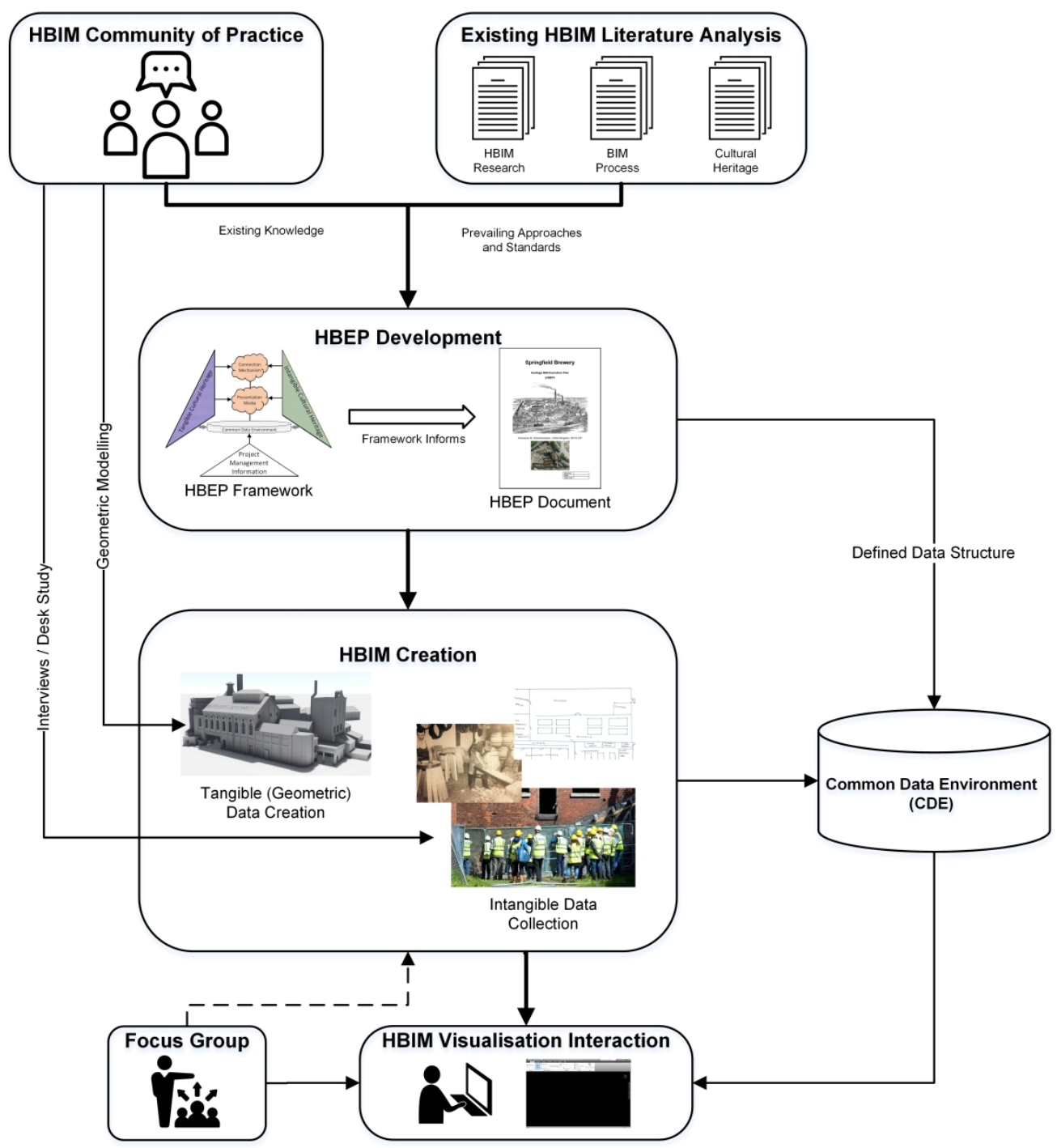

Figure 1: Research approach for the study 


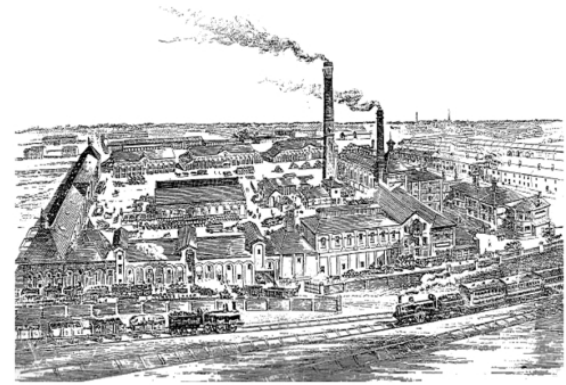

a) Date: 1889

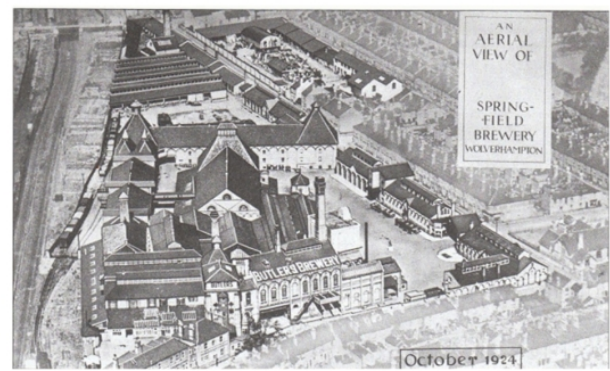

c) Date: 1924

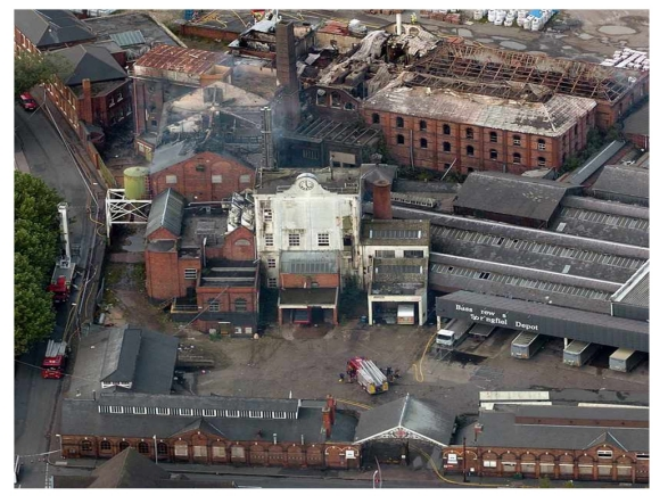

e) Date: 2004

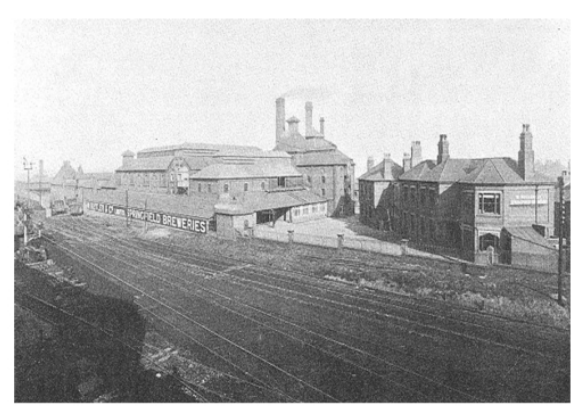

b) Date: 1899

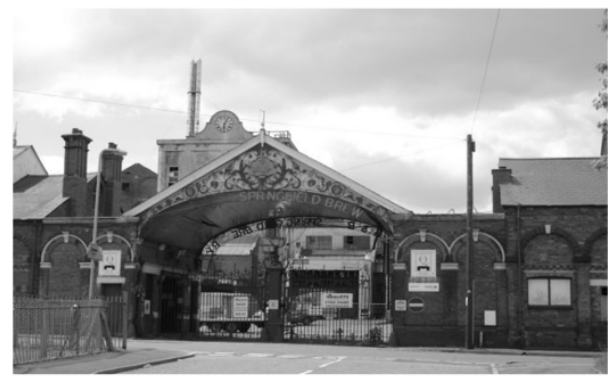

d) Date: Circa 1990

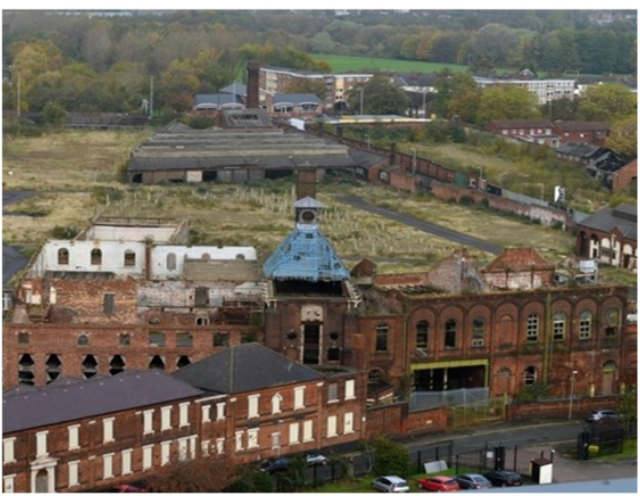

f) Date: 2017

Figure 2: Historical developments of the Springfield site $171 \times 196 \mathrm{~mm}(300 \times 300 \mathrm{DPI})$ 


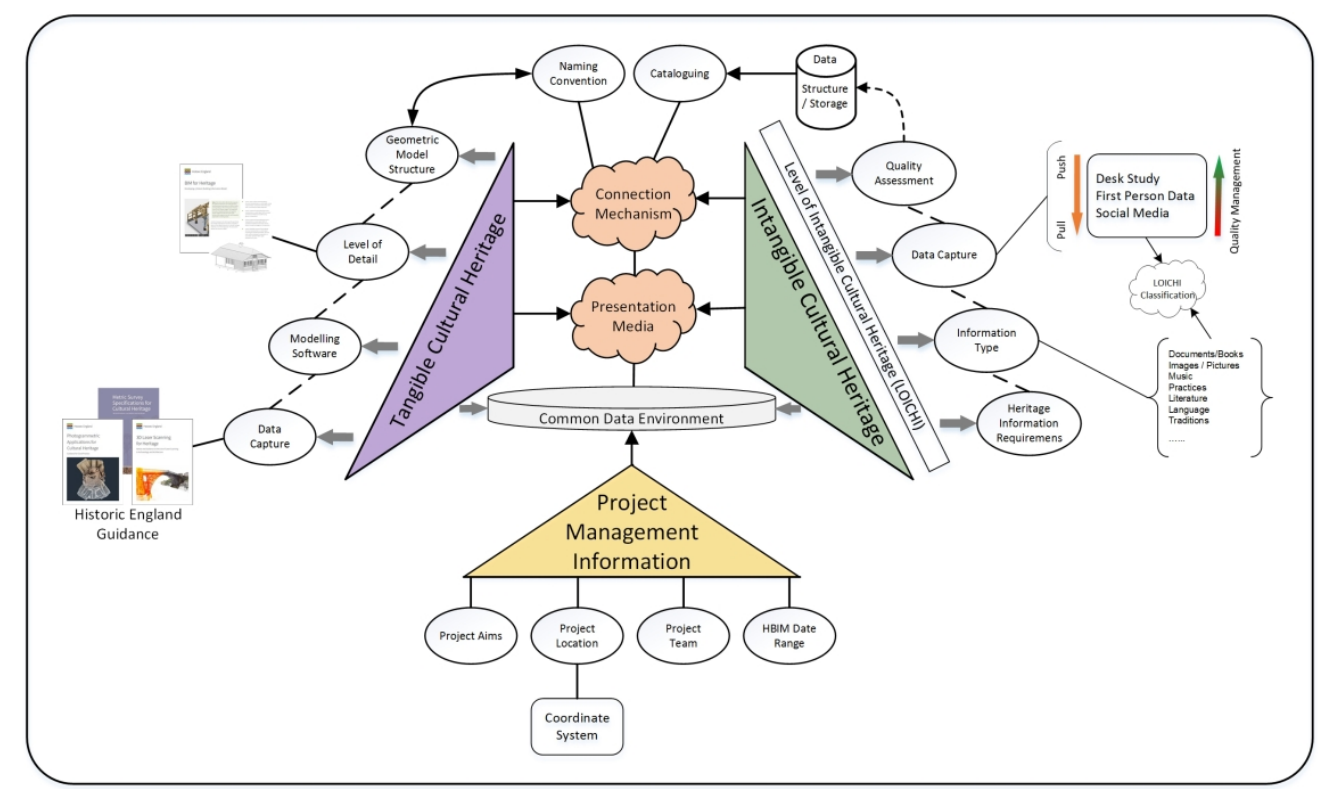

Figure 3: Framework for HBEP development

$224 \times 138 \mathrm{~mm}(300 \times 300 \mathrm{DPI})$ 


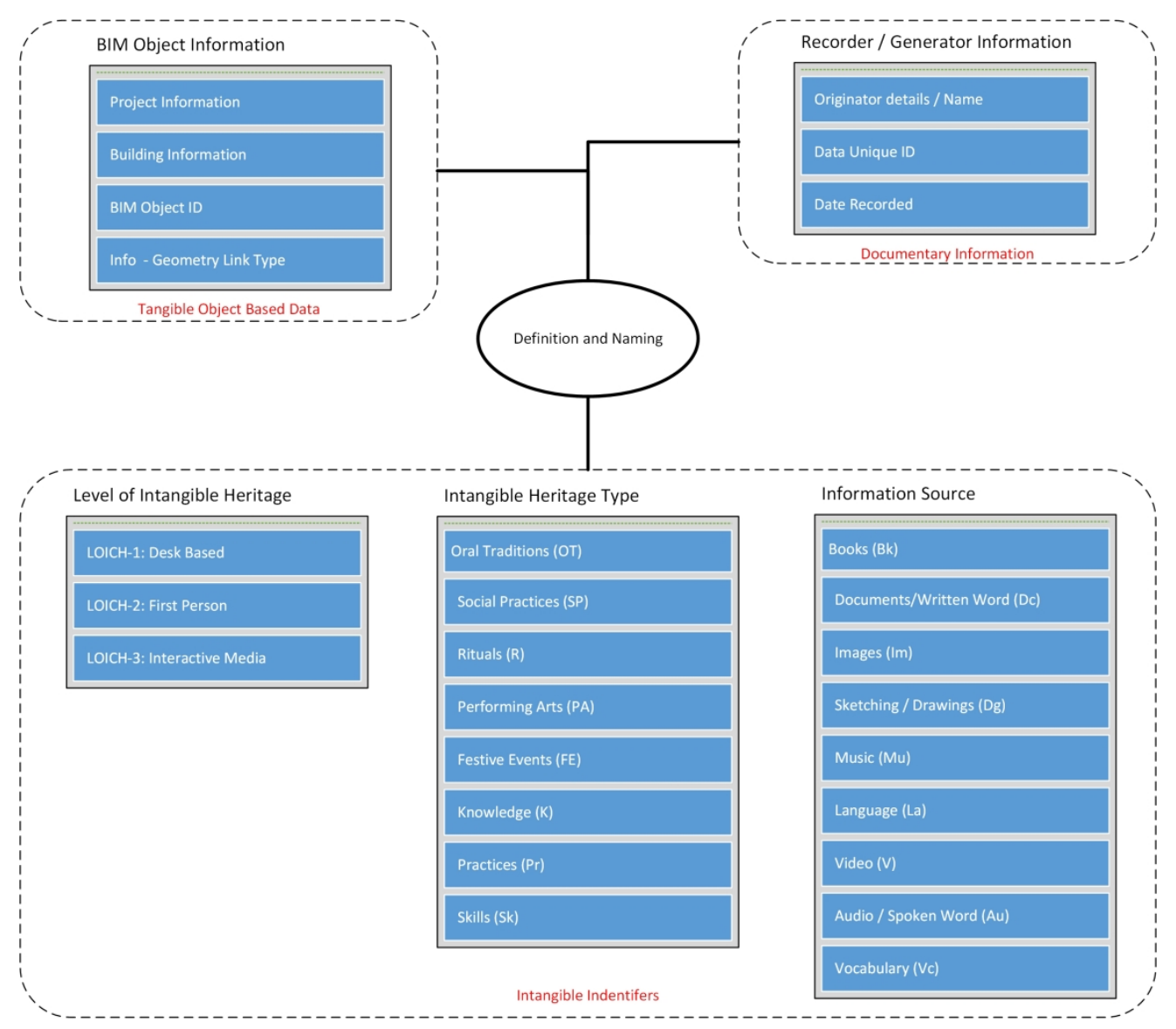

Figure 4: LOICH definition framework and naming convention $245 \times 221 \mathrm{~mm}(300 \times 300 \mathrm{DPI})$ 


\section{Intangible Heritage BIM Naming Generator}

\begin{tabular}{|c|c|}
\hline Project Number / Name & Springfield \\
\hline BIM Geometric Object & Room Level \\
\hline BIM Object ID & L \\
\hline $\mathrm{LOICH}$ & First Person \\
\hline Intangible Heritage Type & Rituals \\
\hline Information Source & Audio / Spoken Word \\
\hline Originator Name & DTH \\
\hline Unique ID & 0001 \\
\hline Date recorded & $01 / 12 / 2017$ \\
\hline
\end{tabular}

Figure 5: Intangible Heritage Container Naming Toolkit

$159 \times 80 \mathrm{~mm}(300 \times 300 \mathrm{DPI})$ 


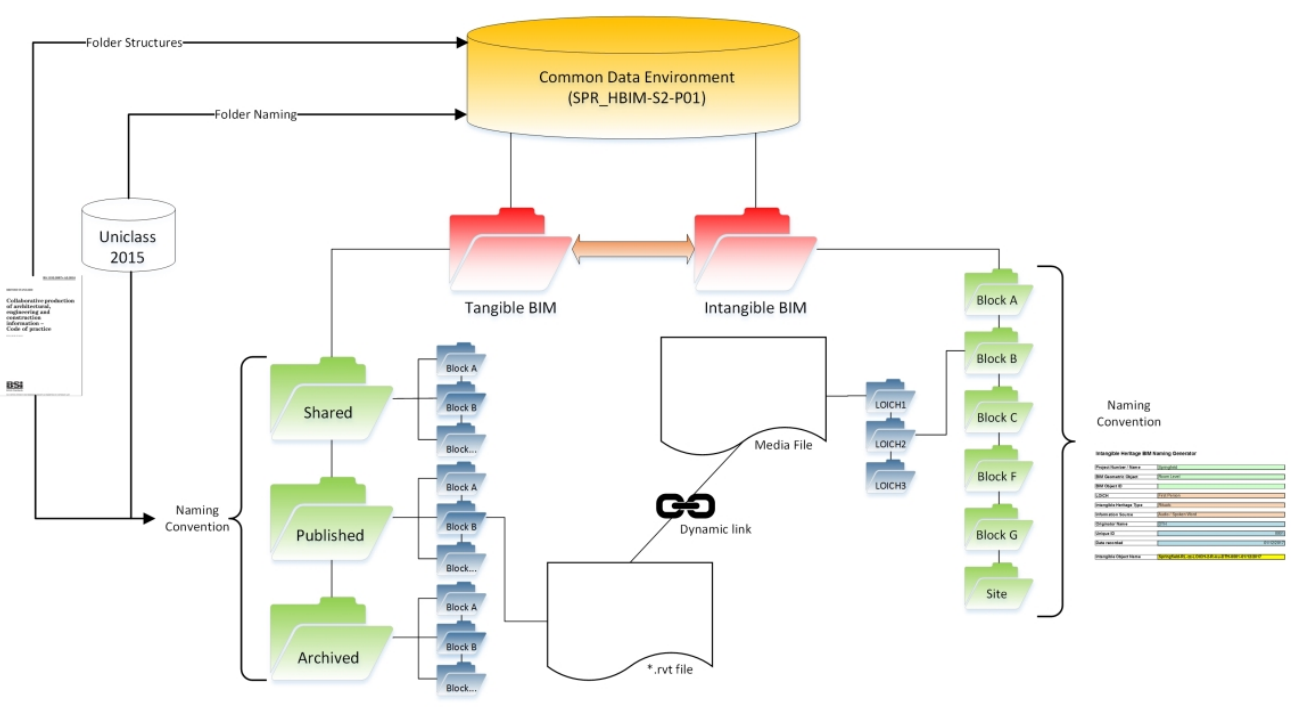

Figure 6: Structuring a CDE for HBIM 265×149mm (300 x 300 DPI) 


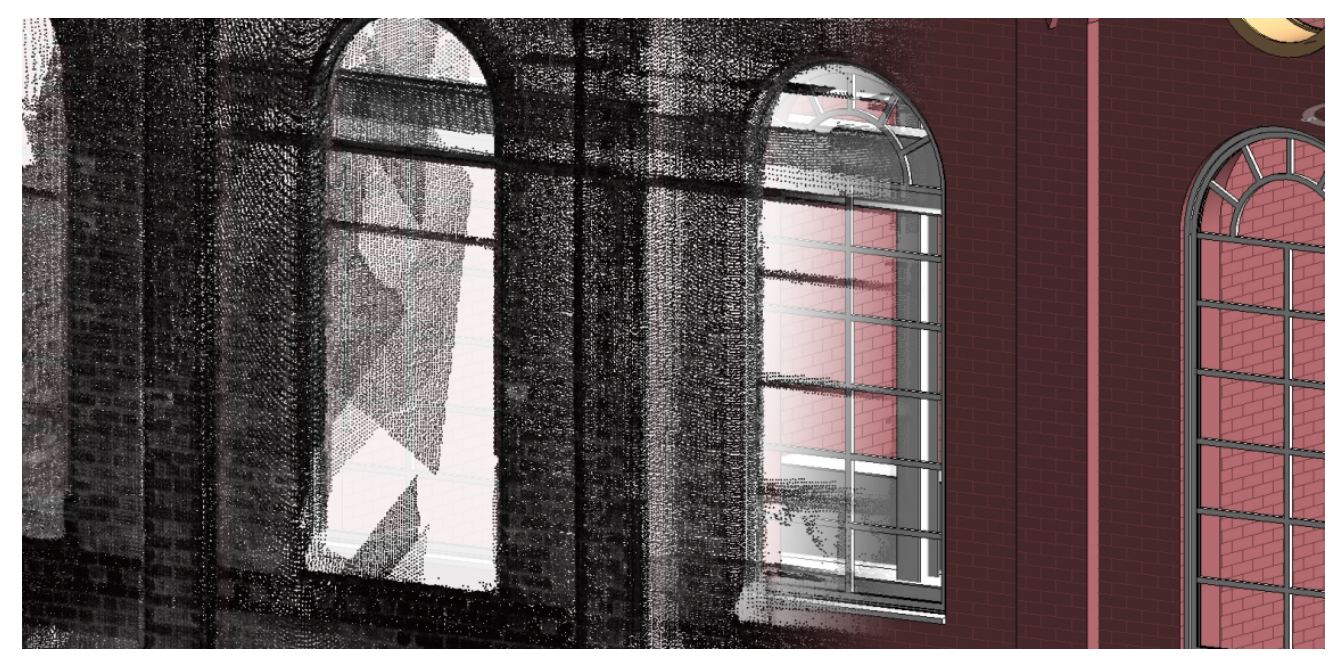

Figure 7: Using Scan to BIM methodologies for geometric modelling existing building 409×198mm (96 x 96 DPI) 

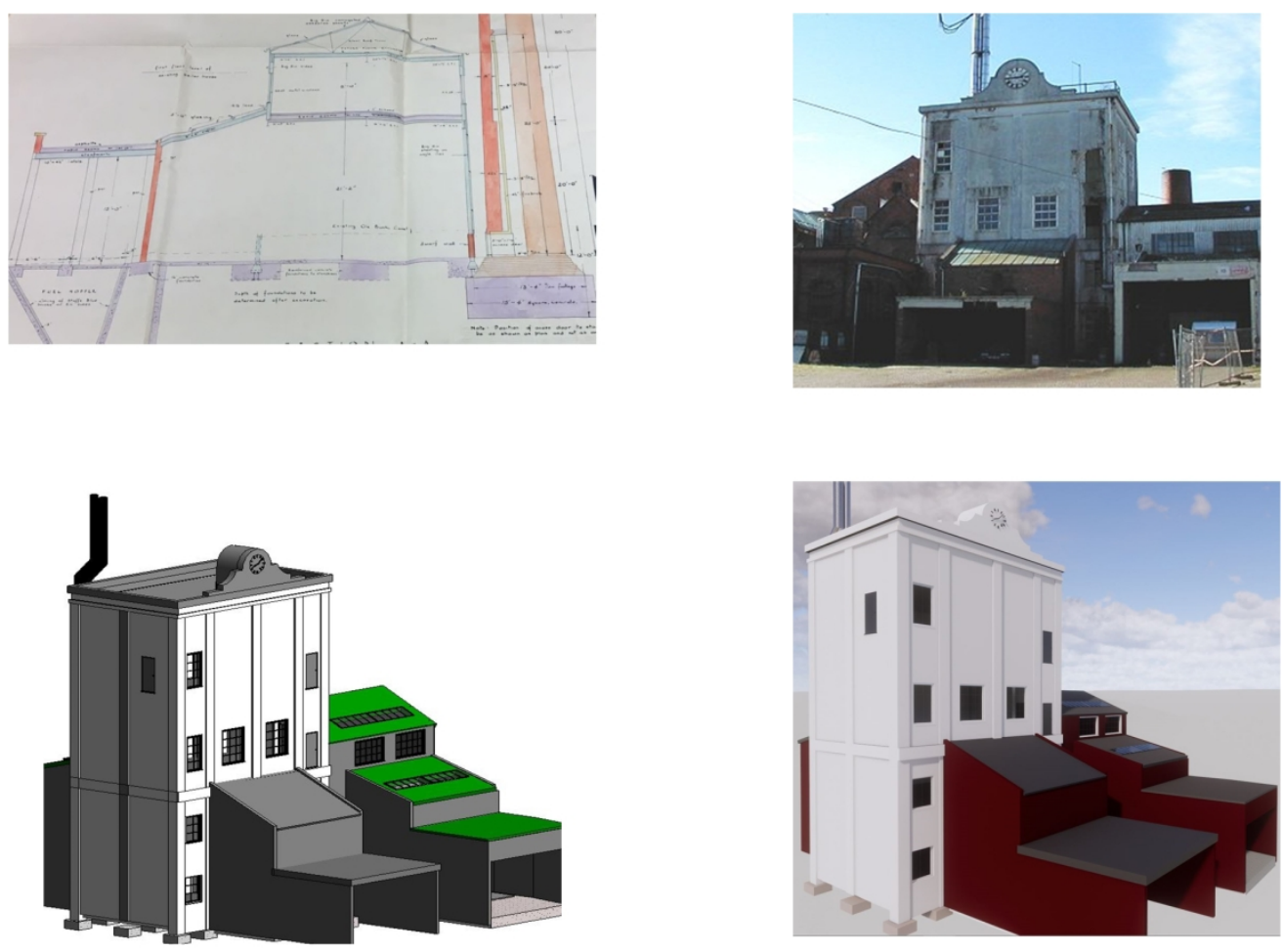

Figure 8: Boiler House no.1 demolished due to 2004 fire damage created from planning drawings and photographs

$159 \times 120 \mathrm{~mm}(300 \times 300 \mathrm{DPI})$ 


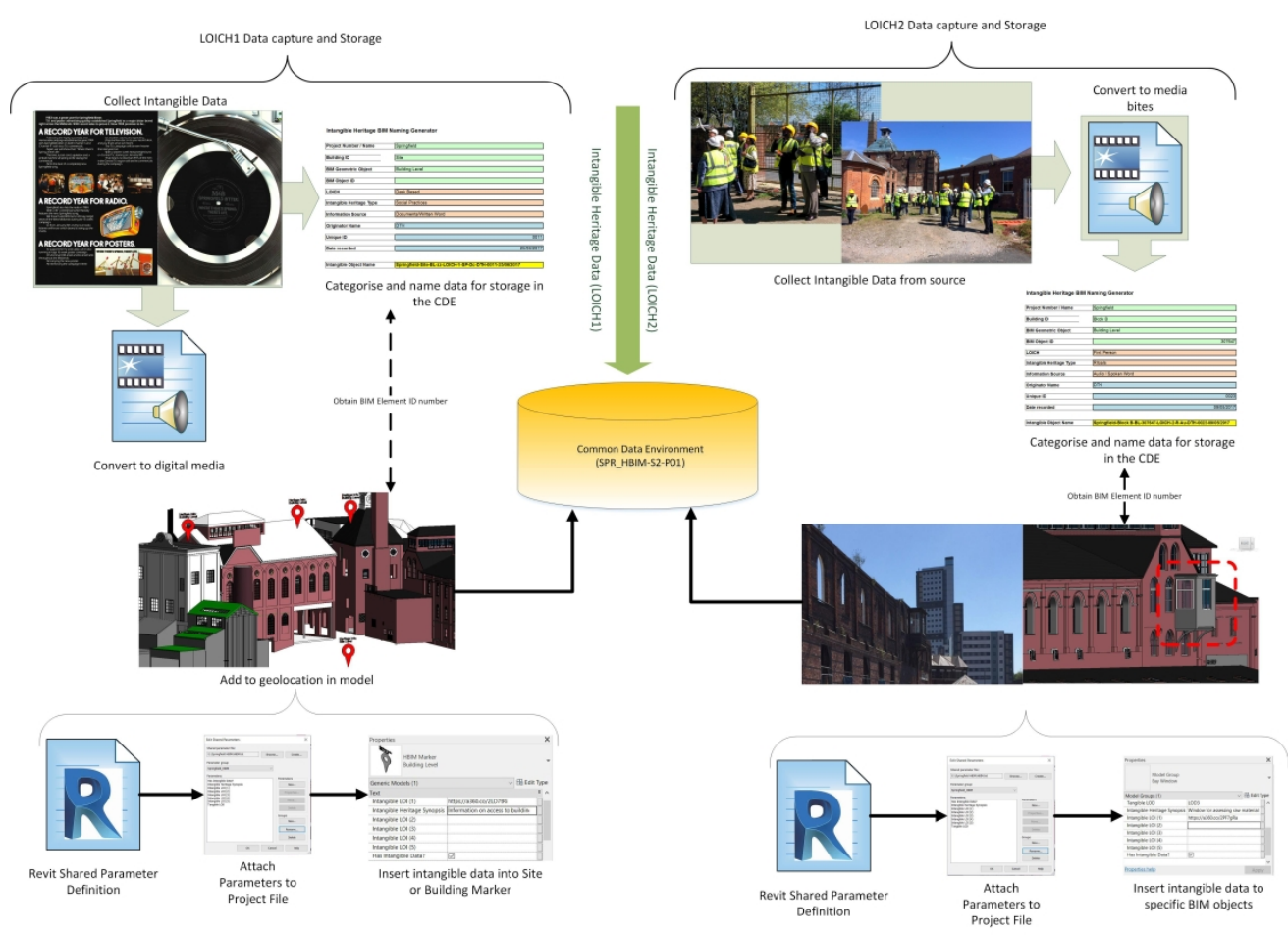

Figure 9: Creating links between Tangible and Intangible data within the HBIM $404 \times 293 \mathrm{~mm}(300 \times 300$ DPI $)$ 

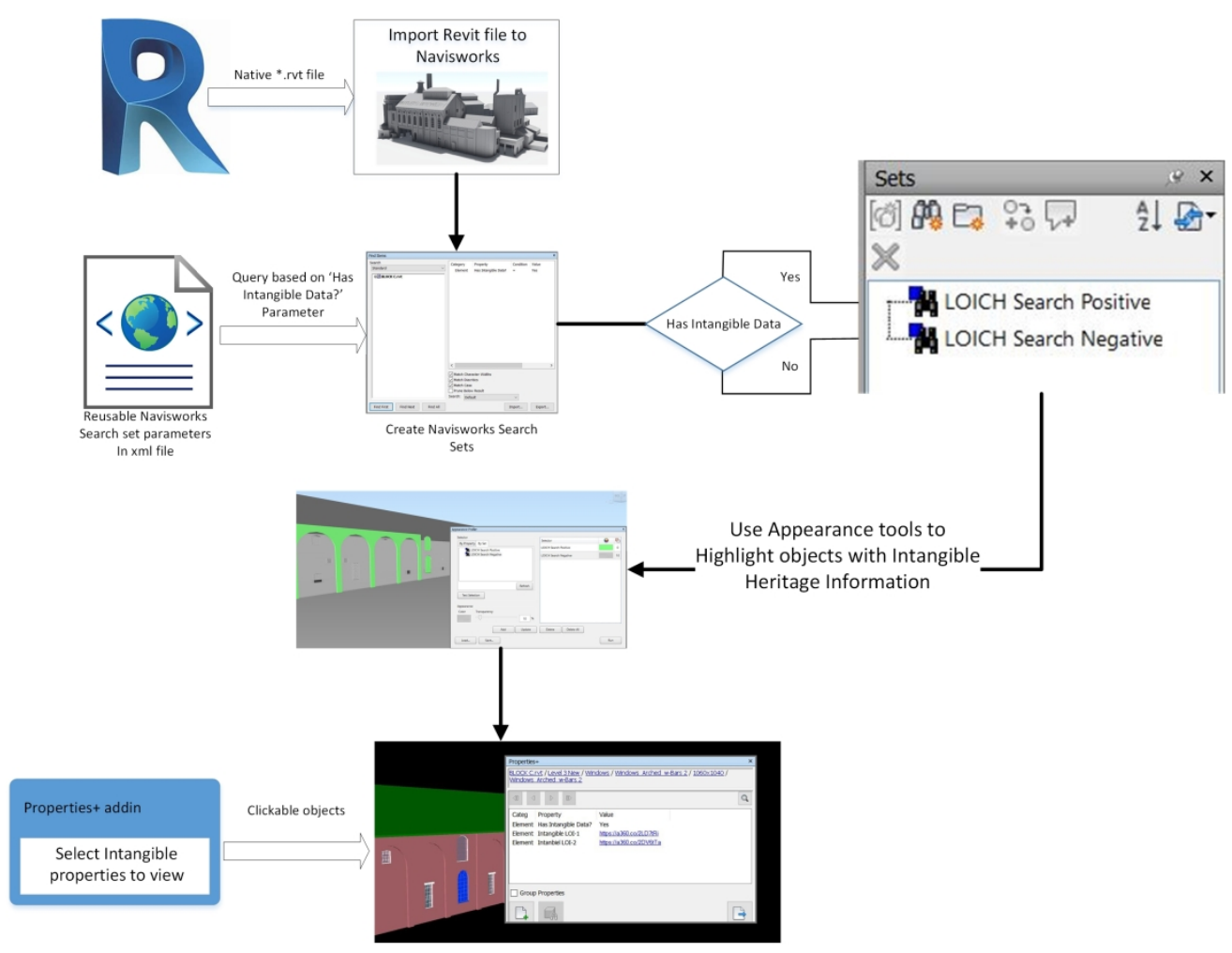

Figure 10: Visualising HBIM data within Autodesk Navisworks $237 \times 183 \mathrm{~mm}(300 \times 300 \mathrm{DPI})$ 